\title{
The Chemokine CCL2 Mediates the Seizure-enhancing Effects of Systemic Inflammation
}

\author{
Chiara Cerri, ${ }^{1,2 \star}$ Sacha Genovesi, ${ }^{3 \star}$ Manuela Allegra, ${ }^{1,2}$ Francesco Pistillo, ${ }^{1}$ Ursula Püntener, ${ }^{4}$ Angelo Guglielmotti, ${ }^{5}$ \\ V. Hugh Perry, ${ }^{4}$ Yuri Bozzi, ${ }^{1,3 \dagger}$ and ${ }^{\circledR}$ Matteo Caleo ${ }^{1 \dagger}$ \\ ${ }^{1}$ Neuroscience Institute, National Research Council, 56124 Pisa, Italy, ${ }^{2}$ Accademia Nazionale dei Lincei, 00165 Rome, Italy, ${ }^{3}$ Laboratory of Molecular \\ Neuropathology, Centre for Integrative Biology, University of Trento, 38123 Trento, Italy, ${ }^{4}$ Centre for Biological Sciences, University of Southampton, \\ Southampton S016 6YD, United Kingdom, and ${ }^{5}$ Angelini SpA, S. Palomba-Pomezia, 00040 Rome, Italy
}

Epilepsy is a chronic disorder characterized by spontaneous recurrent seizures. Brain inflammation is increasingly recognized as a critical factor for seizure precipitation, but the molecular mediators of such proconvulsant effects are only partly understood. The chemokine CCL2 is one of the most elevated inflammatory mediators in patients with pharmacoresistent epilepsy, but its contribution to seizure generation remains unexplored. Here, we show, for the first time, a crucial role for CCL2 and its receptor CCR2 in seizure control. We imposed a systemic inflammatory challenge via lipopolysaccharide (LPS) administration in mice with mesial temporal lobe epilepsy. We found that LPS dramatically increased seizure frequency and upregulated the expression of many inflammatory proteins, including CCL2. To test the proconvulsant role of CCL2, we administered systemically either a CCL2 transcription inhibitor (bindarit) or a selective antagonist of the CCR2 receptor (RS102895). We found that interference with CCL2 signaling potently suppressed LPS-induced seizures. Intracerebral administration of anti-CCL2 antibodies also abrogated LPS-mediated seizure enhancement in chronically epileptic animals. Our results reveal that CCL2 is a key mediator in the molecular pathways that link peripheral inflammation with neuronal hyperexcitability.

Key words: systemic inflammation; temporal lobe epilepsy; CCL2; EEG; seizures

Significance Statement

Substantial evidence points to a role for inflammation in epilepsy, but currently there is little insight as to how inflammatory pathways impact on seizure generation. Here, we examine the molecular mediators linking peripheral inflammation with seizure susceptibility in mice with mesial temporal lobe epilepsy. We show that a systemic inflammatory challenge via lipopolysaccharide administration potently enhances seizure frequency and upregulates the expression of the chemokine CCL2. Remarkably, selective pharmacological interference with CCL2 or its receptor CCR2 suppresses lipopolysaccharide-induced seizure enhancement. Thus, CCL2/CCR2 signaling plays a key role in linking systemic inflammation with seizure susceptibility.

\section{Introduction}

Inflammatory processes within the brain parenchyma are wellknown determinants of seizure propensity (Fabene et al., 2008; Friedman and Dingledine, 2011; Pernot et al., 2011; de Vries et

Author contributions: C.C., S.G., A.G., V.H.P., Y.B., and M.C. designed research; C.C., S.G., M.A., F.P., and U.P. performed research; C.C., S.G., M.A., F.P., and U.P. analyzed data; C.C., S.G., V.H.P., Y.B., and M.C. wrote the paper.

This work was supported by Italian Ministry of Health Grant RF-TAA-2008-1141282 to Y.B. and M.C. and Fondazione Pisa Grant 158/2011 to M.C. C.C. and M.A. are supported by fellowships from Accademia dei Lincei (Rome, Italy). F.P. was supported by a postdoctoral fellowship from Fondazione Veronesi (Milan, Italy). We thank Valentina Adami (High-Throughput Screening Facility, Centre for Integrative Biology, University of Trento, Trento, Italy) and Tarcisio Fedrizzi (Bioinformatics Facility, Centre for Integrative Biology, University of Trento, Trento, Italy) for help with microarray experiments; and Francesca Biondi (National Research Council, Pisa, Italy) for excellent animal care.

A.G. is an Angelini employee. The remaining authors declare no competing financial interests.

${ }^{*}$ C.C. and S.G. contributed equally as first authors.

${ }^{\dagger}$ Y.B. and M.C. contributed equally as senior authors. al., 2012; Devinsky et al., 2013; Vezzani et al., 2013). In particular, seizures upregulate inflammatory mediators in animal models, and increased levels of many cytokines/chemokines such as interleukin-1 $\beta$ (IL-1 $\beta$ ) and C-C motif ligand 2 (CCL2; also known as monocyte chemoattractant protein-1, MCP-1) can be detected in brain tissue of patients with intractable epilepsy (Aronica and Gorter, 2007; Choi et al., 2009). Importantly, brain inflammatory pathways play a key role in recurrence and precip-

Correspondence should be addressed to either of the following: Dr. Matteo Caleo, Neuroscience Institute, National Research Council, via G. Moruzzi 1, 56124 Pisa, Italy, E-mail: caleo@in.cnr.it; or Dr. Yuri Bozzi, Centre for Integrative Biology, University of Trento, via Sommarive 9, 38123 Trento, Italy, E-mail: yuri.bozzi@unitn.it.

S. Genovesi's present address: Armenise/Harvard Laboratory of Cancer Biology and Genetics, Centre for Integrative Biology, University of Trento, Italy.

D0I:10.1523/JNEUROSCI.0451-15.2016

Copyright $\odot 2016$ the authors $\quad 0270-6474 / 16 / 363777-12 \$ 15.00 / 0$ 
itation of seizures (Vezzani et al., 2000; Maroso et al., 2010). For example, IL- $1 \beta$ causes potent proconvulsant effects by mediating enhanced calcium influx through NMDA receptors (Vezzani et al., 2013).

Peripheral inflammatory stimuli can also impact on seizure propensity. Clinical and experimental data provide solid evidence for a role of systemic infection in triggering or sustaining seizures (Cross, 2012; Marchi et al., 2014). Specifically, systemic inflammation reduces the threshold for pharmacologically induced acute seizures in animals (Sayyah et al., 2003; Riazi et al., 2008), and this has been linked to upregulation of proinflammatory cytokines (Riazi et al., 2008).

A systemic inflammatory challenge during a critical period in early development leaves a lasting impact on brain excitability and seizure susceptibility later in life (Galic et al., 2008). Peripheral inflammatory stimuli trigger a local brain inflammatory "mirror" reaction (i.e., cytokine and chemokine production) similar to the response elicited in the periphery (Perry and Holmes, 2014). The diseased brain displays an amplified, exaggerated response to a systemic inflammatory challenge, as a result of glial activation and "priming" (Perry and Holmes, 2014).

We have exploited a systemic inflammatory challenge in animals with chronic mesial temporal lobe epilepsy (MTLE) to identify novel molecular pathways involved in seizure regulation. Microarray and ELISA analyses indicated a potential role for the chemokine CCL2 in mediating seizure upregulation following systemic LPS. Accordingly, functional blocking experiments highlighted a crucial role for CCL2 in inflammation-induced seizures.

\section{Materials and Methods}

Animals. Experiments were conducted in accord with the European Community Directive 2010/63/EU and were approved by the Italian Ministry of Health. Animals were housed in a $12 \mathrm{~h}$ light/dark cycle with food and water available ad libitum. Adult ( $8-12$ weeks old) C57BL/6N male mice were used in all experiments. All efforts were made to minimize animal suffering.

Kainic acid (KA) injection and placement of electrodes. Mice were unilaterally injected with $50 \mathrm{nl}$ of a $20 \mathrm{~mm}$ solution of KA in PBS into the left dorsal hippocampus under Hypnorm/Hypnovel anesthesia (Antonucci et al., 2008, 2009). Stereotaxic injections into the dorsal blade of the dentate gyrus were made at the following coordinates with respect to bregma: anteroposterior -2.0 , mediolateral $1.5,1.7 \mathrm{~mm}$ below dura. Mice were then implanted with a bipolar electrode inserted into the injected hippocampus. The bipolar electrode was formed of two enamelinsulated nichrome wires $(120 \mu \mathrm{m})$. A ground electrode was placed over the cerebellum. Electrodes were connected to a multipin socket and secured to the skull by acrylic dental cement. In a subset of animals, a guide cannula was glued to the bipolar electrode and positioned on top of dura for anti-CCL2 or control IgG injection.

EEG recordings. EEG recordings were performed in freely moving mice during the chronic phase of epilepsy. In all animals, recordings began between 15 and $21 \mathrm{~d}$ after KA. All mice were recorded for $1 \mathrm{~h}$ daily during baseline periods. Mice were then intraperitoneally injected with LPS (L5886, Sigma; from Salmonella enterica, serotype abortus equi; 100 $\mu \mathrm{g} / \mathrm{kg}$ in PBS, $n=7)$ or saline $(n=7)$. Additional EEG recording sessions ( $2 \mathrm{~h}$ long) were made 2 and $24 \mathrm{~h}$ after treatment. For bindarit experiments, after a baseline recording period ( $4-5 \mathrm{~d})$, bindarit $(100 \mathrm{mg} / \mathrm{kg}$ in $0.5 \%$ methylcellulose $[\mathrm{MC}] ; n=10$ mice $)$ or $\mathrm{MC}(0.5 \%$ in aqueous solution; $n=11$ mice) was daily intraperitoneally injected for $4 \mathrm{~d}$. Thirty minutes after the third and the fourth injection, EEG activity was recorded for $30 \mathrm{~min}$. On the fourth day, mice received an intraperitoneal injection of LPS, and EEG recordings were performed between 2 and $4 \mathrm{~h}$ after the systemic challenge. The choice of bindarit dose $(100 \mathrm{mg} / \mathrm{kg})$ was based on our previous studies, showing that a similar dose was able to reduce CCL2 expression in the brain and suppress neuropathological
Table 1. Primers used for qRT-PCR experiments

\begin{tabular}{llll}
\hline Gene & Forward primer $\left(5^{\prime}-3^{\prime}\right)$ & Reverse primer $\left(5^{\prime}-3^{\prime}\right)$ & GenBank \# \\
\hline CCL12 & CTACCACCATCAGTCCTC & TGAATCTTCTGCTTAACAACAT & NM011331 \\
CCL2 & GAGTAGGCTGGAGAGCTACAAGAG & AGGTAGTGGATGCATTAGCTTCAG & NM11333 \\
CCL4 & CTCTCTCCTCTTGCTCGT & GGTCTCATAGTAATCCATCACAA & NM013652 \\
CCL5 & AGAATACATCAACTATTTGGAGA & CCTTGCATCTGAAATTTTAATGA & NM013653 \\
CCR2 & CCAGTAAATGCCATGCAAGTTC & CCGTGGATGAACTGAGGTAAC & NM009915 \\
CXCL10 & GACCATCAAGAATTTAATGAAAGGG & CCATCCACTGGGTAAAGGG & NM021274 \\
IL1 $\beta$ & ACGGACCCCAAAAGATGAAG & TTCTCCACAGCCACAATGAG & NM008361 \\
TLR2 & TGATGGTGAAGGTGGACG & CGGAGGGATAGAGGTGAAG & NM011905 \\
TLR4 & TTCAGAACTTCAGTGGCTGG & TGTTAGTCCAGAGAAACTTCCTG & NM021297 \\
\hline
\end{tabular}

signs of experimental autoimmune encephalomyelitis in vivo (Ge et al., 2012).

To interfere with signaling via the CCL2 receptor, we injected systemically a selective CCR2 antagonist (RS102895; $5 \mathrm{mg} / \mathrm{kg}$, Tocris Bioscience; $n=7$ ) or vehicle ( $4 \%$ DMSO in saline; $n=7$ ) as control. Injections of RS102895/vehicle were given twice (i.e., immediately after and $1.5 \mathrm{~h}$ following LPS delivery in chronically epileptic animals). RS102895 has been previously used as a potent and specific antagonist of CCR2 (Hung et al., 2013; Ren et al., 2015).

In anti-CCL2 experiments, after a baseline recording period ( $2-3 \mathrm{~d})$, mice were injected with goat anti-CCL2 $(1 \mu \mathrm{l}$ of a $100 \mu \mathrm{g} / \mathrm{ml}$ solution; AF-479-NA, R\&D Systems; $n=7)$ or control goat IgG (AB-108-C, R\&D Systems; $n=6$ ) via the implanted microcannula. This blocking antibody has been previously shown to efficiently neutralize the biological activity of CCL2 in vitro and in vivo (e.g., Stamatovic et al., 2006; Fujimoto et al., 2009). One hour after injection, mice received an intraperitoneal LPS injection and EEG recordings were performed between 2 and $4 \mathrm{~h}$ after the systemic challenge.

All recordings were performed between 10:00 A.M. and 6:00 P.M., and care was taken to record from each animal at the same time of the day. Signals were amplified (10,000-fold), bandpass filtered $(0.3-100 \mathrm{~Hz})$, digitized (National Instruments card), and conveyed to a computer for storage and analysis (Antonucci et al., 2008, 2009; Mainardi et al., 2012). Detection of seizures was performed with custom software written in LabView (National Instruments). The program first identified spikes in the EEG using a voltage threshold. This voltage threshold was set to 4.5 times the SD of the EEG signal (determined in a period devoid of spike activity). Spontaneous recurrent seizures (SRSs) were defined as spike clusters lasting for $>4 \mathrm{~s}$, whereas clusters lasting $<4 \mathrm{~s}$ and isolated spikes were considered as interictal events. For each recording session, we determined the frequency and duration of SRS and interictal clusters, the number of single spikes, and the total time spent in seizures or in interictal activity (calculated by adding together the duration of either ictal or interictal episodes) (Antonucci et al., 2008, 2009; Mainardi et al., 2012; Vannini et al., 2015). For histological controls, naive and chronically epileptic animals were deeply anesthetized and perfused with $4 \%$ PFA. Serial coronal sections $(40 \mu \mathrm{m})$ throughout the dorsal hippocampus were processed for Nissl staining.

Tissue dissections for molecular analyses. To analyze mRNA expression changes by microarray and qRT-PCR, KA-injected hippocampi were dissected from epileptic mice during the chronic phase, 4 and $24 \mathrm{~h}$ after LPS or saline intraperitoneal administration. For CCL2 mRNA in situ hybridization and CCL2/CCR2 immunohistochemistry, brains were dissected from KA-treated epileptic mice during the chronic phase, $4 \mathrm{~h}$ after LPS administration. For ELISA experiments, hippocampi were dissected from chronically epileptic and naive animals, $4 \mathrm{~h}$ after LPS or saline administration; at the same time, serum was collected by cardiac puncture from each animal. For ELISA experiments, two additional groups of nonepileptic, naive animals received LPS (100 $\mu \mathrm{g} / \mathrm{kg}$ in PBS) or saline and tissues were collected $4 \mathrm{~h}$ after treatment. In bindarit experiments, epileptic mice received daily intraperitoneal injection of bindarit or MC for $4 \mathrm{~d}$. On the fourth day, $1 \mathrm{~h}$ after bindarit or MC administration, mice were challenged with LPS. Hippocampal tissues and blood were collected $4 \mathrm{~h}$ after LPS delivery. RS102895 was administered immediately after and $1.5 \mathrm{~h}$ following LPS delivery in chronically epileptic animals (see above) and hippocampi were collected $4 \mathrm{~h}$ after LPS. 
A

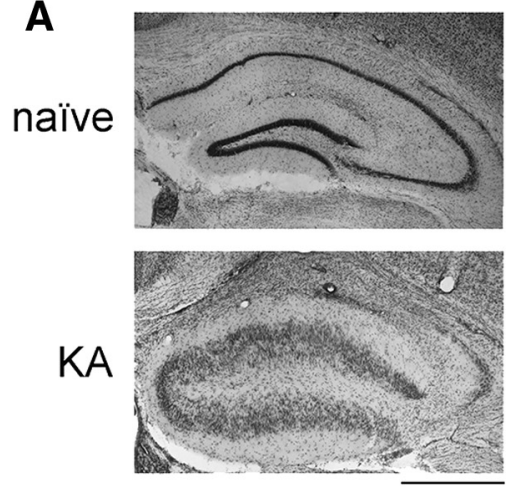

B

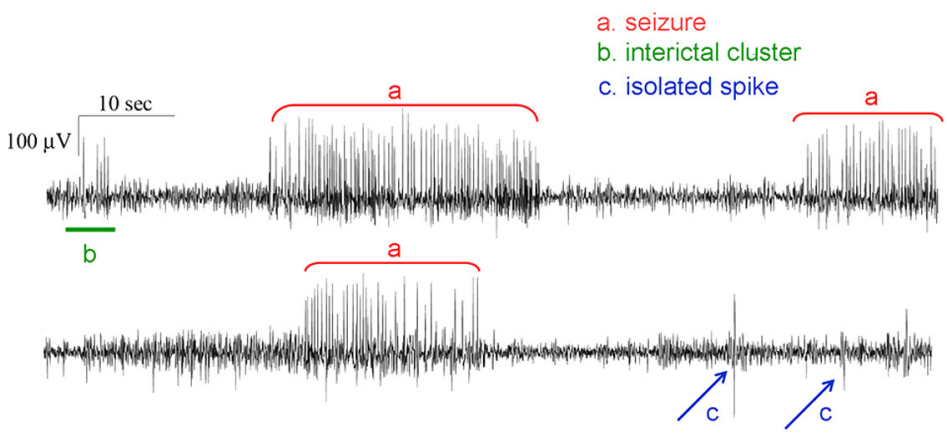

Figure 1. Histopathological changes and EEG seizures in the KA model of MTLE. $A$, Nissl staining in coronal sections from a naive mouse (top) and from a mouse killed $21 \mathrm{~d}$ after intrahippocampal KA (bottom). In the epileptic hippocampus, note the typical granule cell dispersion and extensive neuronal loss in CA1 and CA3. Scale bar, $500 \mu \mathrm{m}$. $\boldsymbol{B}$, Representative EEG recordings displaying activity in the hippocampus during the chronic phase of epilepsy. Three types of epileptiform events are distinguished: seizures (spike clusters lasting for $>4 \mathrm{~s}$; $a$, red), interictal clusters (spike clusters lasting $<4$ s; b, green), and isolated spikes (c, blue).

A
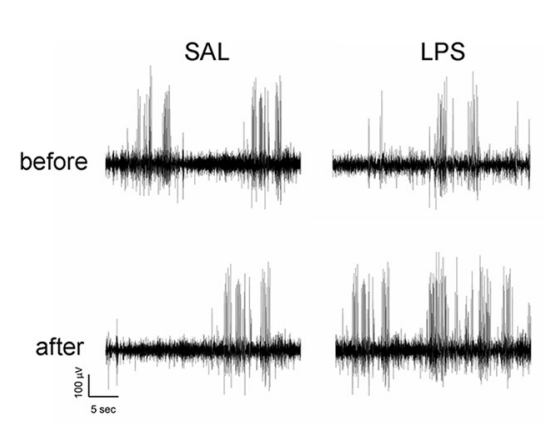

D

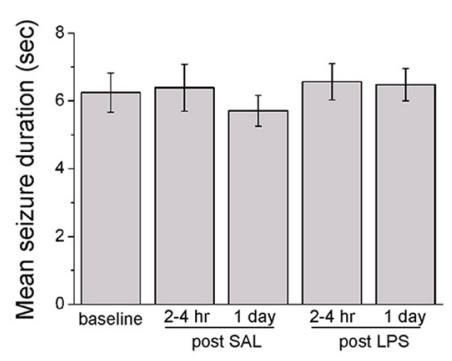

B

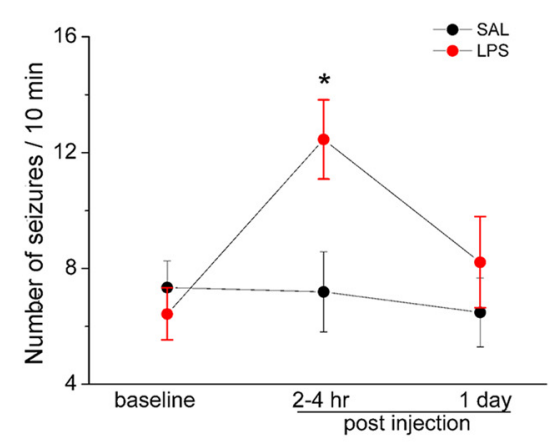

E

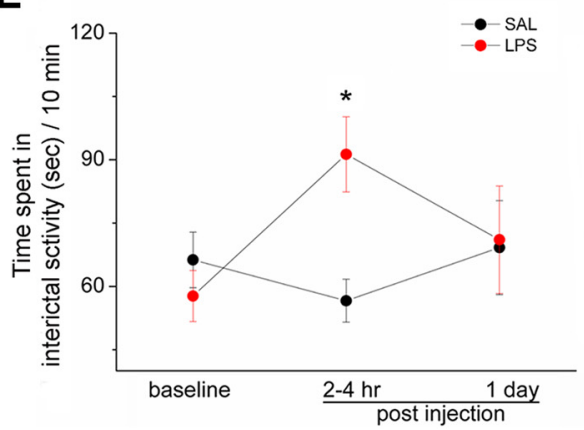

C

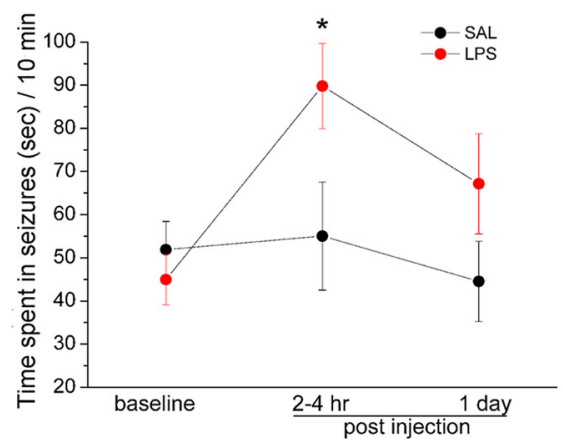

$\mathbf{F}$

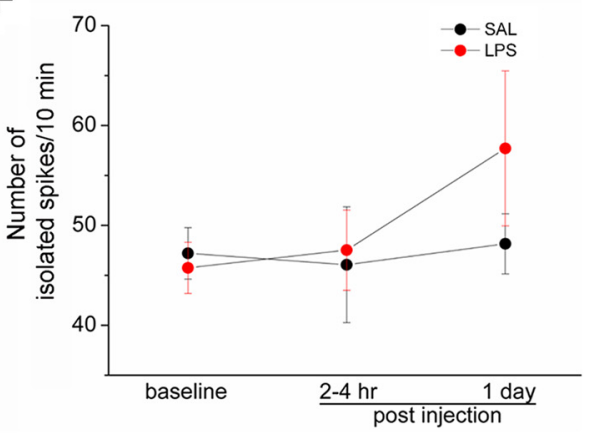

Figure 2. Impact of LPS challenge on the epileptic brain. $\boldsymbol{A}$, Representative intrahippocampal EEG recordings from chronically epileptic mice, before and 2-4h after saline/LPS administration. LPS clearly increases SRS frequency. $\boldsymbol{B}$, Number of EEG seizures per 10 min of recording in epileptic mice, before and after saline (black circles) or LPS (red circles). Seizure frequency is significantly enhanced by LPS (two-way repeated-measures ANOVA followed by Holm-Sidak test, $p<0.05$ ). $C$, Total time spent in ictal activity per 10 min of recording. Epileptic animals treated with LPS significantly spent more time in ictal activity than saline-injected mice (two-way repeated-measures ANOVA followed by Holm-Sidak test, $p<0.05$ ). $\boldsymbol{D}$, Mean duration of EEG seizures in saline- and LPS-treated mice (one way ANOVA; $p=0.7$ ). $\boldsymbol{E}$, Total time spent in interictal activity per $10 \mathrm{~min}$ of recording. Epileptic animals treated with LPS (red circles) significantly spent more time in interictal activity than saline-injected mice (black circle) $2-4 \mathrm{~h}$ following the systemic challenge (two-way repeated-measures ANOVA followed by Holm-Sidak test, $p<0.05$ ). $\boldsymbol{F}$, Number of isolated spikes per $10 \mathrm{~min}$ of recordings. No difference was found between LPS and saline-injected epileptic mice (two-way repeated-measures ANOVA followed by Holm-Sidak test, $p=0.5$ ). Data are \pm SEM. ${ }^{*} p<0.05$.

Microarray analysis. RNAs from dissected hippocampi $(n=4$ per experimental group) were purified using standard column purification according to the manufacturer's protocol (RNAeasy Mini Kit, QIAGEN). RNA quality was analyzed by microfluidic gel electrophoresis on RNA 6000 NanoChips using the Agilent 2100 Bioanalyzer. Only RNA with a high (>9) RNA integrity number was selected and used for subsequent retrotranscription, labeling, and array hybridization according to Agilent protocols. Mouse gene expression arrays (Agilent $4 \times 44 \mathrm{~K}$ slides) were hybridized and scanned with the Agilent microarray station. Intensity values were processed with GeneSpring GX software (Agilent) using de- fault parameters to remove low-quality probes (Sgadò et al., 2013). Signals were then normalized by means of the quantile normalization method, and data were statistically filtered by two-way ANOVA imposing a fold change $\geq 2$ for each gene in at least one of the four experimental data groups. Differentially expressed genes were classified by DAVID software, applying Benjamini-corrected $p$ value cutoff of 0.05 . Gene classification was performed according the Kyoto Encyclopedia of Genes and Genomes (KEGG; http://www.genome.jp/kegg/), Panther Molecular Function (http://www.pantherdb.org/panther/ontologies.jsp), and GOterm Molecular Function (http://geneontology.org) databases. 
A

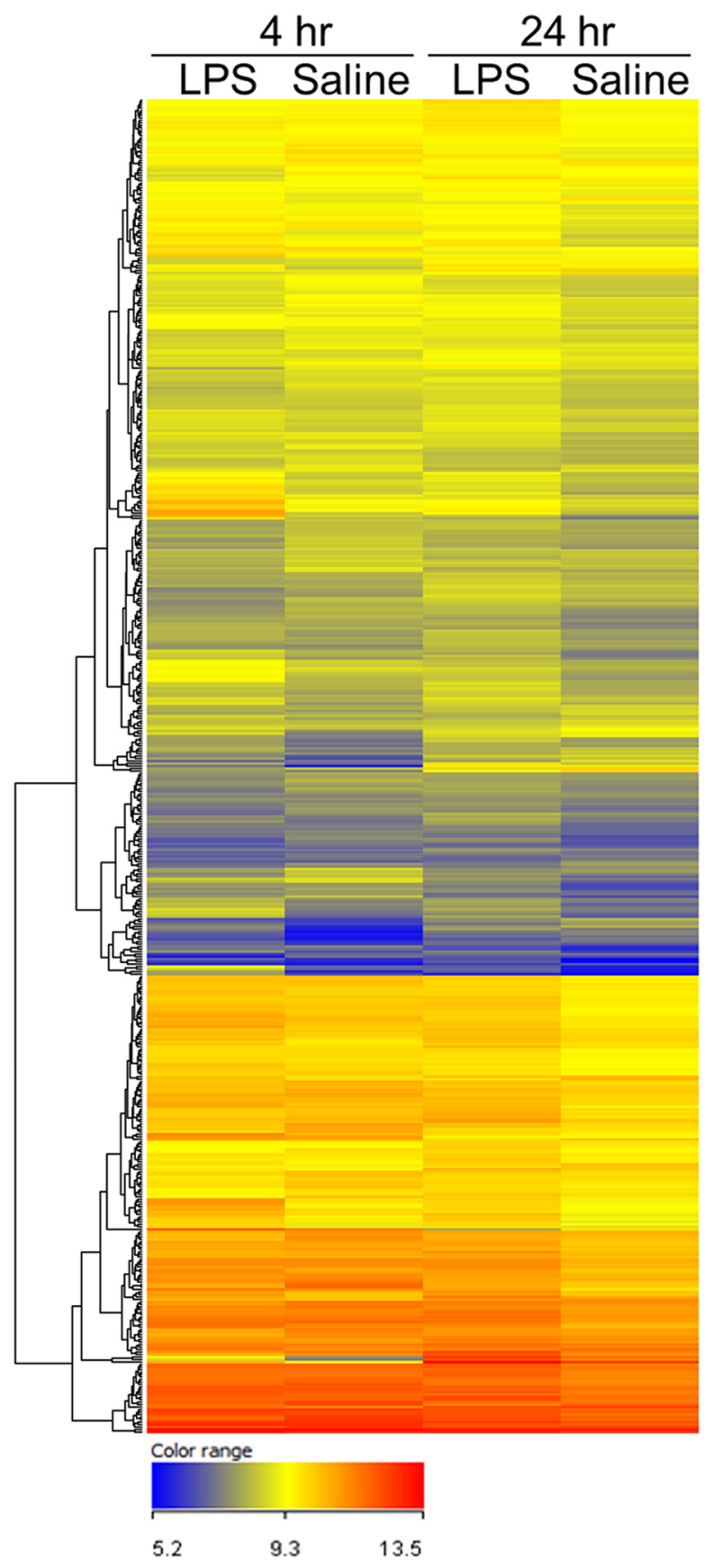

B

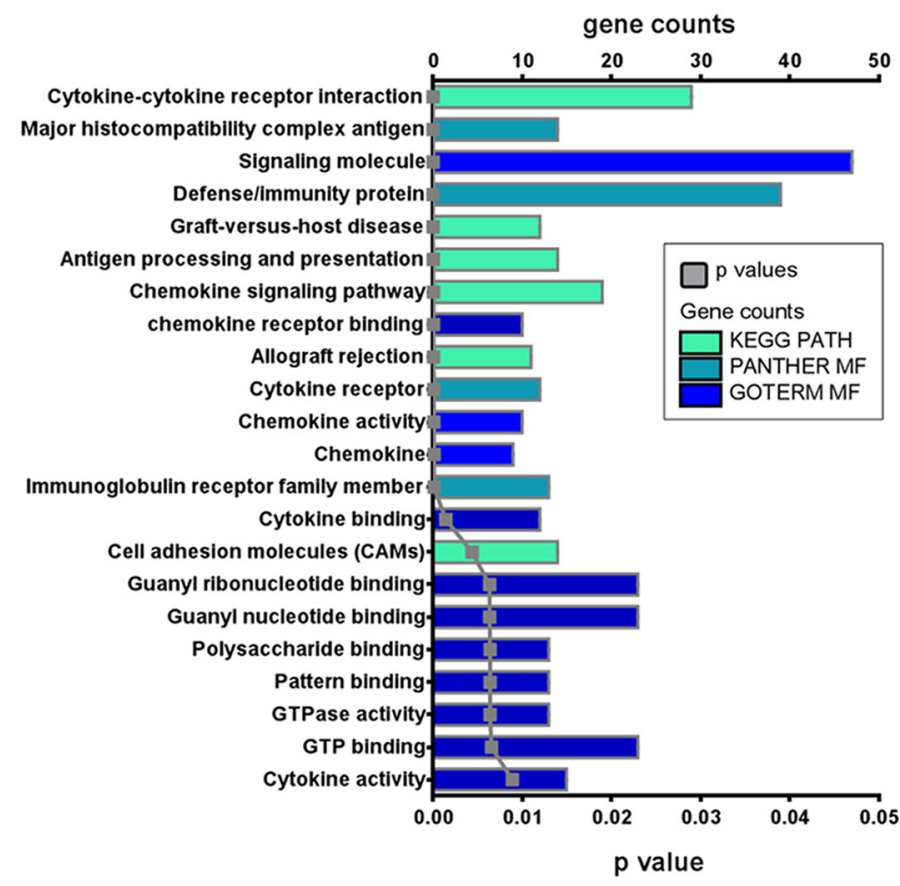

Figure 3. Gene expression changes triggered by systemic LPS in the epileptic hippocampus. A, Microarray heat map of the 533 genes differentially expressed at both 4 and $24 \mathrm{~h}$ in the hippocampus of LPS- versus saline-treated epileptic mice. A color code scale was used to show gene expression differences in logarithmic fold change units between the groups (blue represents lowest expression; red represents higher expression). $\boldsymbol{B}$, Overrepresented gene ontology categories of genes differentially expressed in the hippocampus of LPS-versus saline-treated chronically epileptic mice, at both 4 and $24 \mathrm{~h}$ after treatment. Differentially expressed genes ( 533 in total) were classified by DAVID software, applying Benjamini-corrected $p$ value cutoff of 0.05 . The most significant categories are displayed at the top of the graph to downward ( $p$ value, gray line) and gene number arranged horizontally by the length of the bars (gene counts, colored bars). KEGG PATH, PANTHER MF, and GOTERM MF indicate the databases used for gene classification (KEGG, Panther Molecular Function, and GOterm Molecular Function, respectively; for details, see Materials and Methods).

$q R T-P C R$. Total RNAs were extracted by Trizol reagent (Invitrogen) from explanted hippocampi ( $n=4$ mice per experimental group). DNase-treated RNAs were purified by RNA extraction RNAeasy Kit (QIAGEN). cDNA was synthesized from pooled RNAs by SuperScript VILO cDNA Synthesis Kit (Invitrogen) according to the manufacturer' instructions. qRT-PCR was performed in a C1000 Thermal Cycler (Bio-Rad) with real-time detection of fluorescence, using the KAPA SYBR FAST Master Mix reagent (KAPA Biosystems). Mouse mitochondrial ribosomal protein L41 (mRPL41) was used as a standard for quan- tification. Primer sequences (Sigma Genosys) are reported in Table 1. Ratios of comparative concentrations of each mRNA with respect to L41 mRNA were then calculated and plotted as the average of three independent reactions (technical replicates) obtained from each RNA. Expression analyses were performed using the CFX3 Manager (Bio-Rad) software (Sgadò et al., 2013).

ELISA. Hippocampi ( $n=4-6$ mice per experimental group) were homogenized in a Tris buffer containing a protease inhibitor mixture $(150 \mathrm{~mm} \mathrm{NaCl}, 25 \mathrm{~mm}$ Tris, $1 \%$ Triton X-100 pH 7.4, complete 

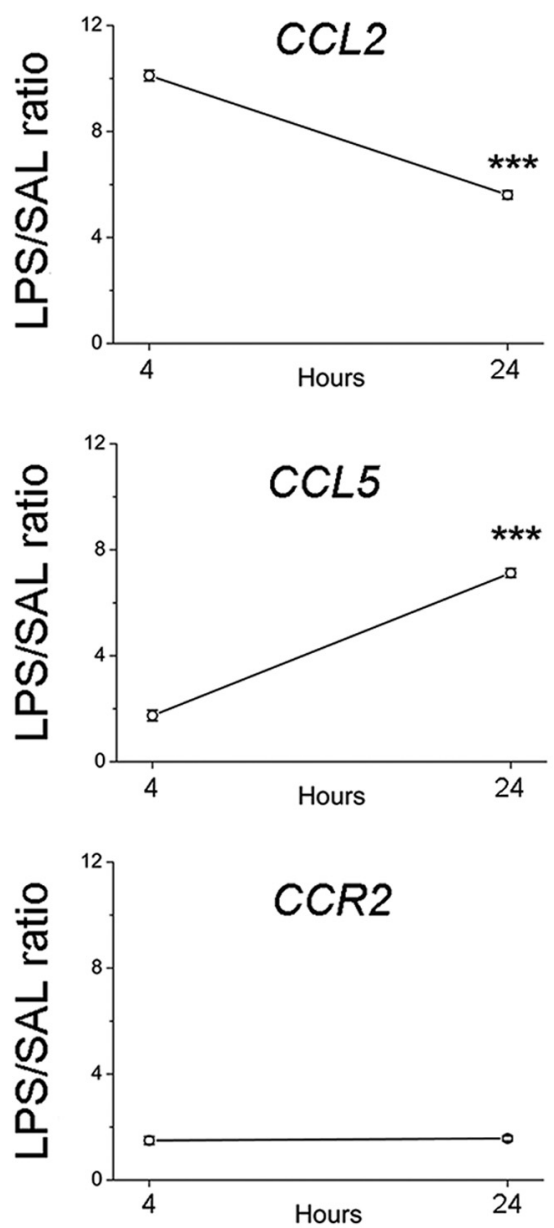
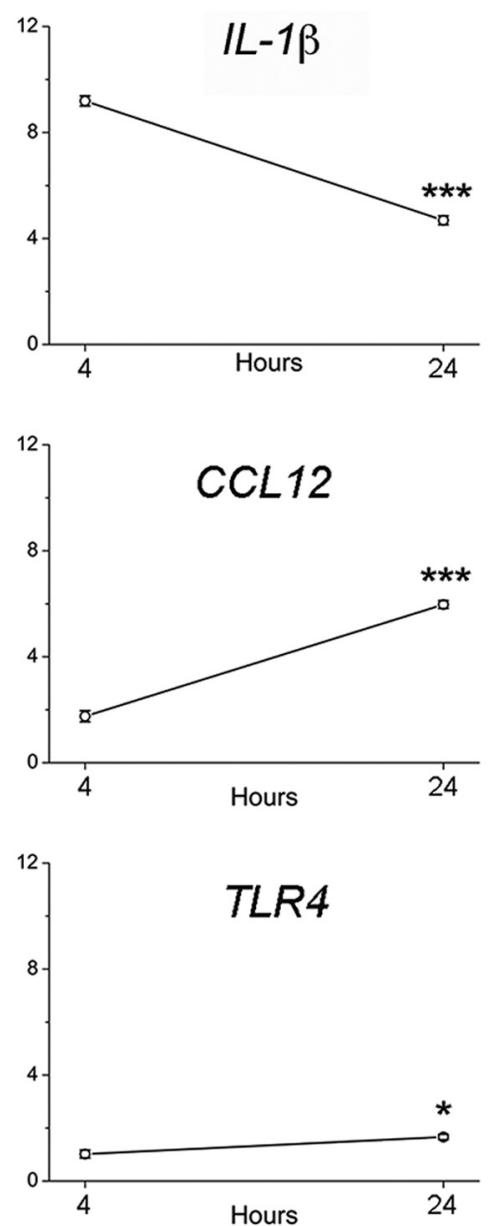
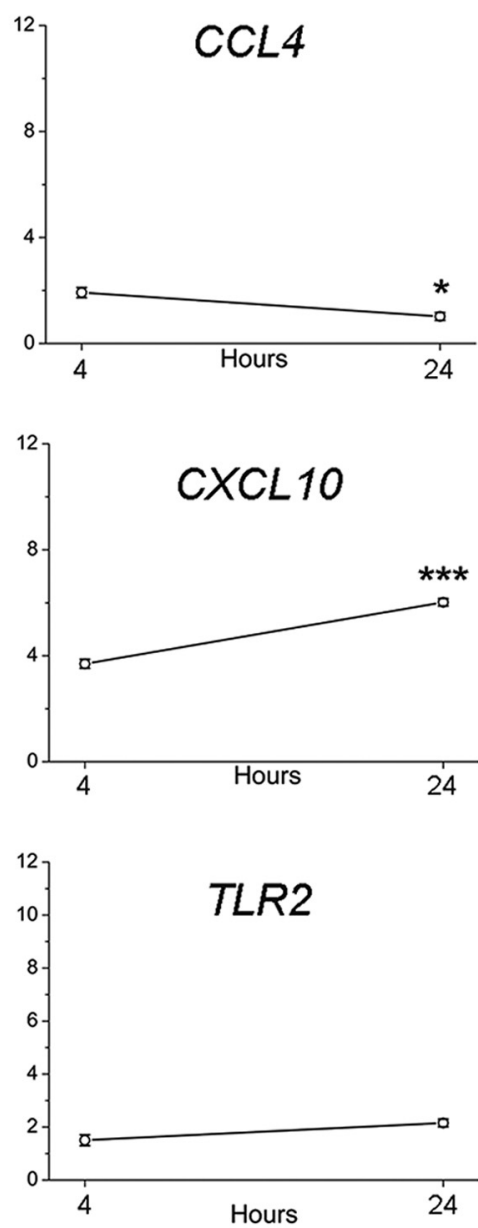

Figure 4. CCL2 and other inflammatory genes are upregulated in the hippocampus of LPS-treated epileptic mice. qRT-PCR validation of microarray experiments; plots represent the mRNA expression of 9 inflammatory genes differentially expressed (upregulated) in the hippocampus of LPS-treated epileptic mice. Values are plotted as the fold increase in LPS- versus saline-treated chronically epileptic mice (LPS/SAL ratio). CCL2 mRNA was 10-fold upregulated in LPS-treated epileptic hippocampus $4 \mathrm{~h}$ after LPS administration, with a significant decrease of $44.5 \%$ at $24 \mathrm{~h}$ (two-way ANOVA followed by Tukey's test, $p<0.001$ ). ${ }^{*} p<0.05 ;{ }^{* * *} p<0.001$.

protease inhibitor mixture; Roche Diagnostics). Samples were centrifuged for $30 \mathrm{~min}$ at $15,000 \times \mathrm{g}$, and supernatants assayed for total protein content using a Pierce BCA protein assay kit (Thermo Fisher Scientific). Cytokine levels in tissue and serum samples $(n=4-6$ mice per experimental group, each sample in triplicate) were assessed using MSD multiplex kit for mouse proinflammatory cytokines (K15012B; Meso Scale Discovery). CCL2 protein quantitation in blood and hippocampal extracts was performed using CCL2 ready-set-go ELISA kit (eBioscience), according to the manufacturer's instructions.

CCL2 mRNA in situ hybridization. Brains from 3 chronically epileptic mice were rapidly removed and frozen on dry ice, $4 \mathrm{~h}$ after LPS challenge. Coronal cryostat sections ( $20 \mu \mathrm{m}$ thick) were fixed in $4 \%$ PFA. Nonradioactive in situ hybridization was performed as previously described (Tripathi et al., 2009) using a mix containing a CCL2 (GenBank ID: NM 011333.1) digoxigenin-labeled riboprobe. Signal was detected by alkaline phosphatase-conjugated anti-digoxigenin antibody followed by alkaline phosphatase staining. The specificity of the results was confirmed by the use of sense riboprobes (data not shown). Images were acquired using a Zeiss Axio Observer z1 microscope.

Immunostaining. Immunohistochemical characterization of CCL2 and CCR2 protein expression was performed on brains from 3 chronically epileptic mice treated with LPS. Brains were fixed by transcardial perfusion with $4 \%$ PFA followed by $1 \mathrm{~h}$ postfixation at $4^{\circ} \mathrm{C}$, and coronal sections ( $40 \mu \mathrm{m}$ thick) were cut on a vibratome. Serial sections at the level of the dorsal hippocampus were incubated overnight with appropriate antibodies (all from Abcam: CCL2, 1:200 dilution; CCR2, 1:200 dilution; CD68, 1:400 dilution). Signals were revealed with biotin- conjugated secondary antibody and streptavidin conjugated to appropriate fluorophores (AlexaFluor-488/-594, Invitrogen). Images were acquired using a Zeiss Axio Observer z1 microscope.

Immunoblotting. To assess NF-kB phosphorylation, hippocampal proteins from LPS $(n=4)$ and LPS+RS $(n=6)$ treated mice were extracted with lysis buffer ( $1 \%$ Triton X-100, 10\% glycerol, 20 mM Tris HCl, pH 7.5, $150 \mathrm{~mm} \mathrm{NaCl}, 10 \mathrm{~mm}$ EDTA, $1 \mu \mathrm{g} / \mathrm{ml}$ leupeptin, $1 \mathrm{mg} / \mathrm{ml}$ aprotinin, $1 \mathrm{~mm}$ PMSF, PhosSTOP Roche phosphatase inhibitors mixture). Protein concentration was determined through BCA protein assay kit (Euroclone). Equal amounts of each sample $(30 \mu \mathrm{g})$ were separated on $4 \%-12 \%$ precast gels (Invitrogen), transferred to nitrocellulose membranes, blocked, and then incubated with primary antibody overnight at $4^{\circ} \mathrm{C}(\mathrm{p} 65,1: 1000$, Cell Signaling Technology; phospho p65 S536, 1:1000, Cell Signaling Technology; and actin 1:8000, Sigma-Aldrich). Secondary antibodies (anti-rabbit Ly-Cor IRDye800RD; anti-mouse Ly-Cor IRDye680RD) were used at 1:10,000 dilution for $1 \mathrm{~h}$ at room temperature.

The membranes were dried overnight in the dark at room temperature and the signal was measured using an Odyssey CLx-Infrared Imaging System. The signal intensity of immunoblotting bands was quantified using iStudio software. Data are mean \pm SEM.

Statistical analyses. For EEG experiments, statistical analysis was performed by two-way repeated-measures ANOVA followed by HolmSidak test for post hoc comparisons. Two-way ANOVA followed by Tukey test was used for comparing gene expression at $4 / 24 \mathrm{~h}$ following LPS/saline treatment. One-way ANOVA (followed by Dunn's or HolmSidak test) was used for comparing mean seizure duration and cytokine/ chemokine concentrations in blood and hippocampi. Differences 
A

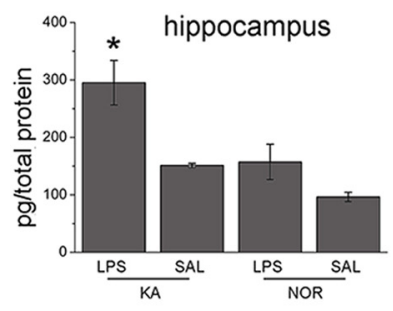

CCL2

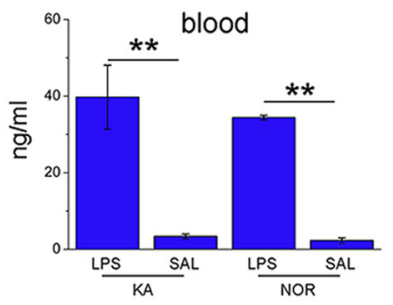

TNF $\alpha$
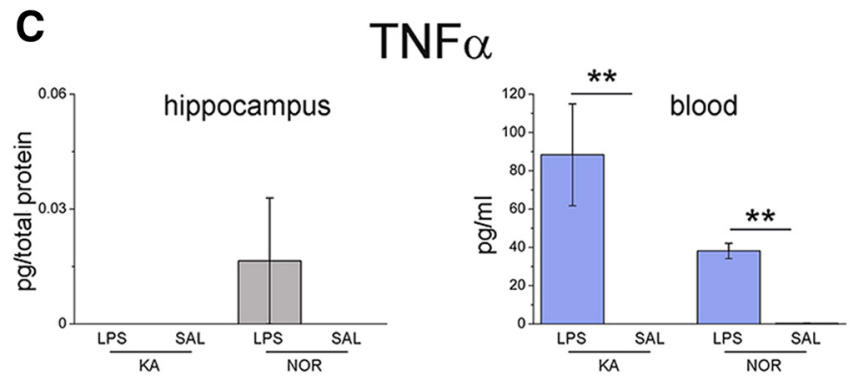

B

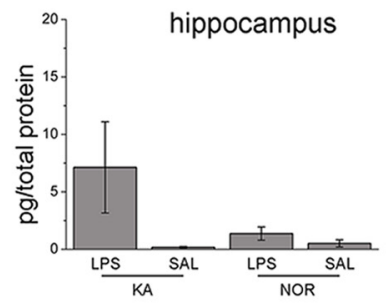

IL-1 $\beta$

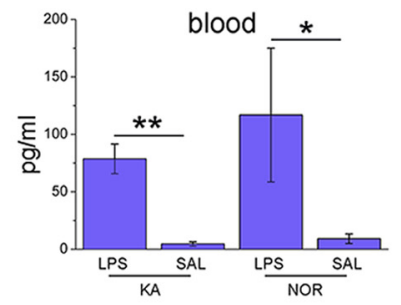

D

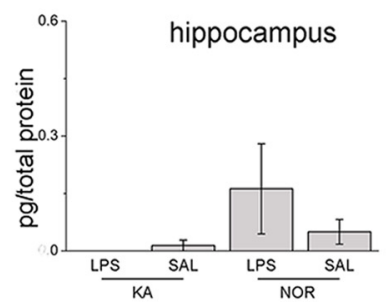

Interferon $\gamma$

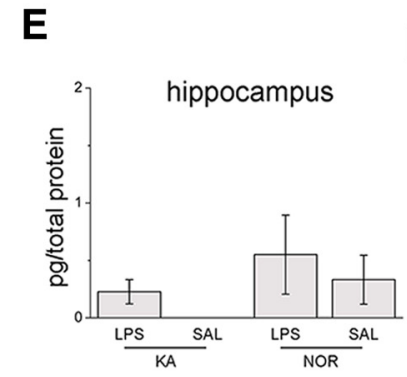

\section{IL-10}

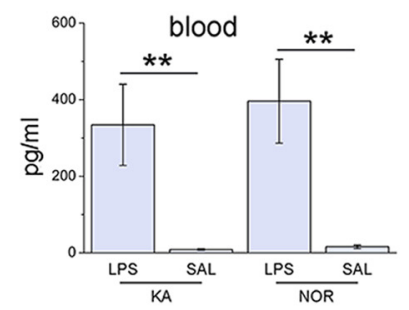

Figure 5. Cytokine/chemokine concentrations in blood and hippocampus of epileptic and naive mice, $4 \mathrm{~h}$ after LPS/saline treatment. $A, B$, LPS increased the levels of CCL2 and IL-1 $\beta$ in the blood of both epileptic and naive mice (one-way ANOVA, $p<0.05$ ). $A$, In the hippocampus, CCL2 expression was more robustly upregulated in epileptic versus naive mice (one-way ANOVA followed by Holm-Sidak test, $p<0.05$ ). $\boldsymbol{B}$, IL-1 $\beta$ showed a similar but nonsignificant trend (one way ANOVA followed by Dunn's test $p>0.05)$. C $-\boldsymbol{E}$, TNF $\alpha$, interferon- $\gamma$, and IL-10 were upregulated in the blood of LPS-treated mice (one-way ANOVA followed by Dunn's test, $p<0.01$ ), but no consistent mirror response was observed in hippocampal samples of either naive or epileptic animals (one-way ANOVA, $p>0.4) .{ }^{*} p<0.05 ;{ }^{* *} p<0.01$.

between two groups were assessed with Student's $t$ test because our data were normally distributed. For microarray data analysis, DAVID (http:// david.abcc.ncifcrf.gov) was used to assess for functional categories overrepresented in the differentially expressed 533 common genes between 4 and $24 \mathrm{~h}$ dataset. Pairwise comparisons of qRT-PCR and immunoblotting data were assessed by a two-tailed Student's $t$ test. Level of significance was set at $p<0.05$.

\section{Results}

\section{Systemic inflammation enhances spontaneous seizures}

MTLE was induced by unilateral injection of KA into the adult mouse hippocampus (Riban et al., 2002; Antonucci et al., 2008). All experiments were conducted during the chronic phase of epilepsy (i.e., starting from 2 weeks after KA), when the injected side presents typical hippocampal sclerosis (Fig. 1A), and EEG recordings show frequent SRSs, interictal clusters, and isolated spikes (Fig. 1B).

We first examined the impact of a systemic inflammatory challenge on seizure activity. Baseline SRS were recorded for $4-5 \mathrm{~d}$ before intraperitoneal treatment with LPS $(100 \mu \mathrm{g} / \mathrm{kg})$ or saline (SAL) as control. EEG recordings were performed 2-4 h after systemic challenge (i.e., when the behavioral response to LPS is highest, Teeling et al., 2007) and at $24 \mathrm{~h}$. We found that injection of saline had no effect on SRS at either time point, whereas injection of LPS clearly increased seizure incidence within $4 \mathrm{~h}$ (two-way repeated-measures ANOVA followed by Holm-Sidak test, $p<0.05$; Fig. $2 A, B$ ). Total time spent in ictal and interictal activity was also significantly in- creased by LPS ( $p<0.05$; Fig. $2 C, E)$. Interestingly, the inflammatory challenge did not impact on mean seizure duration and frequency of isolated spikes (one way ANOVA, $p=0.6$; Fig. $2 D, F$ ). LPS effects were transient, as mice recorded $24 \mathrm{~h}$ after treatment showed a return to the baseline, pre-LPS level of seizures and interictal discharges (post-ANOVA Holm-Sidak test, $p>0.05$; Fig. $2 B, C, E$ ).

\section{CCL2 upregulation in the epileptic hippocampus following LPS}

We then performed a microarray analysis to investigate the gene expression pathways activated by LPS in KA-injected hippocampi. To this purpose, we compared the transcriptomic profile of chronically epileptic hippocampi in LPS- versus salinetreated mice. The expression profile of epileptic hippocampi markedly differed between LPS- and saline-treated animals, at both 4 and $24 \mathrm{~h}$ after treatment (Fig. 3A). A total of 533 genes were differentially expressed in epileptic hippocampi at both 4 and $24 \mathrm{~h}$ after LPS, compared with saline-treated animals; pathway analysis revealed that most of these differentially expressed genes belong to chemokine/cytokine pathways (Fig. 3B). We next used qRT-PCR to validate nine of these differentially expressed genes. Compared with saline-treated epileptic mice, CCL2 and $I L-1 \beta$ mRNA were 10 -fold and 8-fold, respectively, upregulated in LPS-treated epileptic mice $4 \mathrm{~h}$ after LPS administration, significantly decreasing at $24 \mathrm{~h}$ (two-way ANOVA followed by Tukey's test, $p<0.0001$; Fig. 4). CCL4 mRNA was only 1.9-fold upregu- 
A

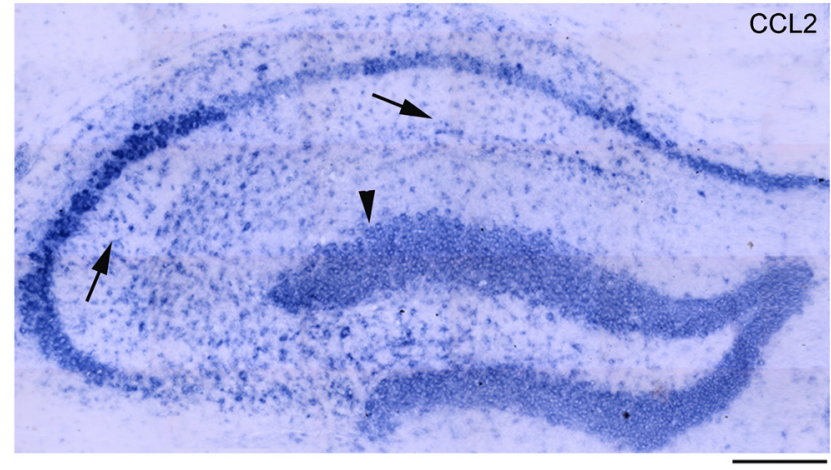

B
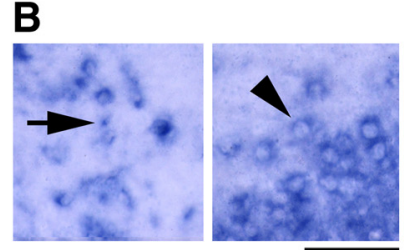

C

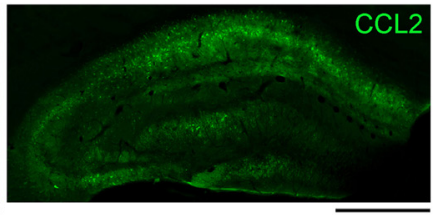

D
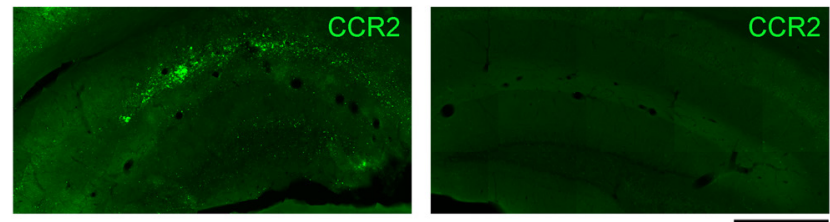

E
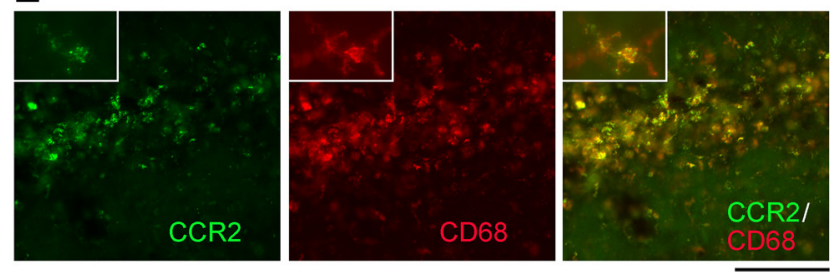

Figure 6. Cellular localization of $C \mathrm{CL} 2$ and $C C R 2$ in the sclerotic hippocampus after LPS. $\boldsymbol{A}-\boldsymbol{C}$, $\mathrm{CCL} 2 \mathrm{mRNA}(\boldsymbol{A}, \boldsymbol{B})$ and protein $(\boldsymbol{C})$ staining on representative sections from the dorsal hippocampus of an epileptic mouse, $4 \mathrm{~h}$ after LPS. CCL2 staining is present in pyramidal neurons, dispersed granule cells of the dentate gyrus $(\boldsymbol{A}, \boldsymbol{B}$, arrowhead) and several small, likely glial cells of stratum oriens, stratum radiatum $(\boldsymbol{A}, \boldsymbol{B}$, arrows), stratum lacunosum moleculare, and hilus. Details of labeled cells are shown in $\boldsymbol{B}$. Left, CA1 stratum radiatum. Right, Dentate granule cells. Scale bars: $\boldsymbol{A}, 200 \mu \mathrm{m} ; \boldsymbol{B}, 40 \mu \mathrm{m} ; \boldsymbol{C}, 600 \mu \mathrm{m}$. $\boldsymbol{D}$, Immunostainings of CCR2 on representative sections from the epileptic (left) and contralateral (right) hippocampus, $4 \mathrm{~h}$ after LPS. CCR2 staining is mainly restricted to the CA1 subfield and dentate gyrus of the epileptic hippocampus and is absent from the contralateral side. Scale bar, $600 \mu \mathrm{m}$. $\boldsymbol{E}$, Immunostainings of CCR2 (green), CD68 (red), and their colocalization (yellow) on a representative section from the CA1 subfield of an epileptic mouse, $4 \mathrm{~h}$ after LPS. Expression of CCR2 in activated microglia/macrophages, as indicated by $C C R 2 / C D 68$ colocalization (yellow), is evident in high-magnification figures shown in insets. Scale bar: $150 \mu \mathrm{m}$; insets, $30 \mu \mathrm{m}$.

lated in LPS-treated mice at $4 \mathrm{~h}$ and returned to basal levels $24 \mathrm{~h}$ after LPS administration (two-way ANOVA followed by Tukey's test, $p=0.02$ ). The chemokines CCL5, CCL12, and CXCL10 showed a stronger upregulation at $24 \mathrm{~h}$ with respect to $4 \mathrm{~h}$ (twoway ANOVA followed by Tukey's test, $p<0.0001)$. The CCL2 receptor CCR2 as well as the Toll-like receptors TLR4 and TLR2 showed modest changes in LPS-treated mice (Fig. 4). Together, the strong increase of $C C L 2$ and $I L-1 \beta$ expression at the time of LPS-induced seizure aggravation $(4 \mathrm{~h})$ points to a possible involvement of these molecules in mediating LPS effects.

We then analyzed CCL2 and IL- $1 \beta$ protein levels $4 \mathrm{~h}$ following LPS challenge (Fig. $5 A, B$ ) using ELISA. LPS increased CCL2 and IL- $1 \beta$ levels in the blood of both epileptic and naive mice (Fig.
$5 A, B)$. Analysis of hippocampal samples revealed a strong "priming" effect, with CCL2 expression more robustly upregulated in the hippocampus of epileptic versus naive mice (one-way ANOVA followed by Holm-Sidak test, $p<0.05$; Fig. $5 A$ ). Similar results were obtained for IL- $1 \beta$ in the blood, whereas IL- $1 \beta$ levels did not differ significantly in the hippocampus of epileptic or naive mice treated with LPS (Fig. 5B). Multiplex ELISA revealed a robust upregulation of TNF $\alpha$, interferon- $\gamma$, and IL-10 in the blood of LPS-treated mice, but increases in the brain were extremely modest and independent of the epileptic phenotype (Fig. $5 C-E)$. These data indicate selectivity in the "mirror" inflammatory cascades triggered by a systemic challenge within the epileptic brain, and a potential role of CCL2 in translating the CNS effects of systemic inflammation.

We next examined the cell populations expressing CCL2 and its receptor CCR2 in the epileptic hippocampus. CCL2 mRNA in situ hybridization and immunostaining indicated expression of CCL2 in pyramidal neurons and dispersed granule cells of the dentate gyrus following LPS challenge (Fig. $6 A-C$ ). Several small, likely glial cells of stratum oriens, stratum radiatum, stratum lacunosum moleculare, and hilus were also labeled (Fig. 6A,B). Immunohistochemical localization of CCR2 was found predominantly in activated microglia/macrophages within the sclerotic tissue (Fig. 6D,E), consistent with a role for CCR2 in microglia and monocyte recruitment (Shi and Pamer, 2011; Cunningham, 2013).

\section{Interference with CCL2/CCR2 signaling abrogates LPS-}

\section{induced seizure enhancement}

We next asked whether interfering with CCL2 would prevent the enhancement of chronic seizures following systemic LPS treatment. We first used the anti-inflammatory drug bindarit that preferentially inhibits transcription of the monocyte chemoattractant subfamily of CC chemokines, including CCL2 (Mirolo et al., 2008; Ge et al., 2012; Mora et al., 2012). We recorded baseline EEG seizure activity; then epileptic animals received daily intraperitoneal injections of bindarit (100 mg/kg) (Ge et al., 2012) or vehicle solution (MC) for $4 \mathrm{~d}$. EEG recording sessions were performed $30 \mathrm{~min}$ after the third and the fourth daily injection. At the end of the recording session on the fourth day, mice were challenged with LPS and recorded 2-4 h later (Fig. 7A). Recordings performed before LPS challenge showed that seizure frequency and total time spent in seizures were unaltered by either bindarit or vehicle with respect to baseline (two-way repeatedmeasures ANOVA followed by Holm-Sidak test, $p>0.05$; Fig. $7 B, C)$. Importantly, LPS triggered the expected seizure upregulation in controls but failed to do so in animals treated with bindarit (two-way repeated-measures ANOVA, bindarit vs control, $2-4 \mathrm{~h}$ after LPS, $p<0.01$; Fig. $7 B, C$ ). Mean seizure duration following LPS administration was unaffected by either bindarit or vehicle treatment (one-way ANOVA, $p=0.3$; Fig. $7 D$ ). The LPS-induced increase in interictal discharges was also abolished by bindarit (Fig. $7 E$ ), whereas the number of isolated interictal spikes did not vary between bindarit- and vehicle-treated epileptic mice (Fig. $7 F$ ). Thus, treatment with bindarit abolishes the seizure-enhancing effect of systemic inflammation.

To probe the effects of bindarit at the molecular level, we collected epileptic hippocampi and blood samples from bindaritand vehicle-treated mice, $4 \mathrm{~h}$ after LPS delivery. ELISA showed that CCL2 protein was reduced by $77.4 \%$ in blood of bindarittreated animals, compared with control mice ( $t$ test, $p=0.01$; Fig. $8 A)$. qRT-PCR confirmed this reduction at the mRNA level $(p<$ 0.001; Fig. $8 B$ ). In blood samples, bindarit also dampened CCL5 

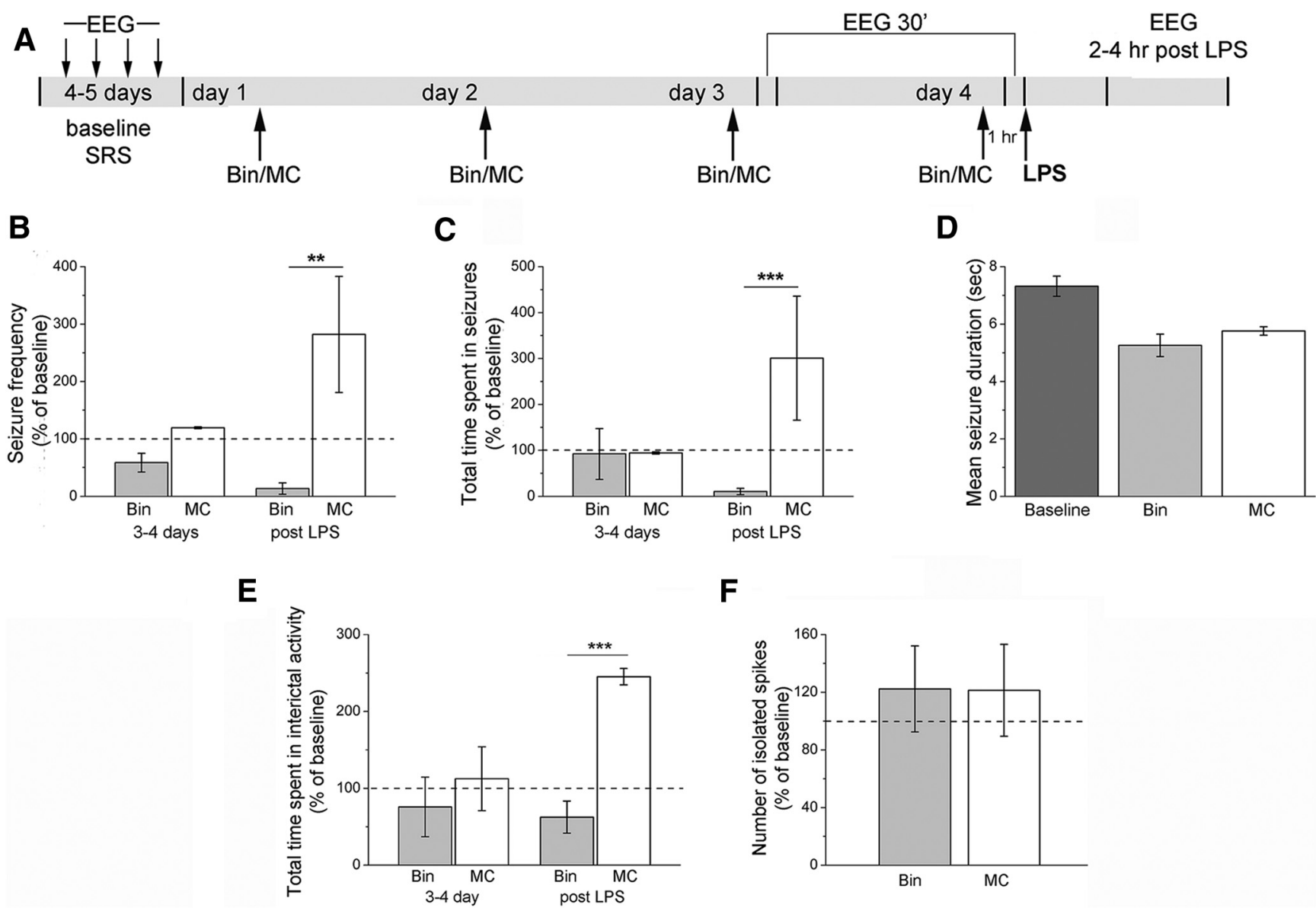

$\mathbf{F}$

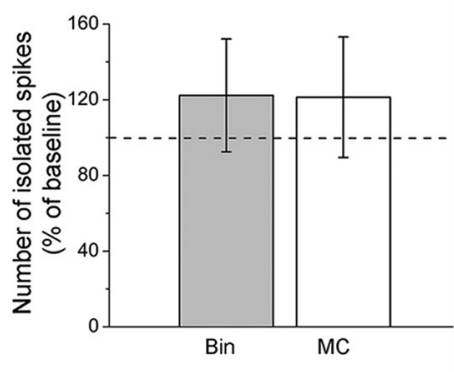

Figure 7. Treatment with bindarit abolishes the seizure-enhancing effect of LPS. $A$, Experimental protocol. After baseline assessment of SRS, animals were treated daily with either bindarit (Bin) or vehicle (MC) and injected systemically with LPS on the fourth day. B, C, Frequency of seizures and total time spent in ictal activity per 10 min of recording (normalized to the baseline period). Before LPS treatment (3- $4 \mathrm{~d}$ ), seizure frequency and total time spent in seizures were unaltered by either bindarit or vehicle with respect to baseline (two-way repeated-measures ANOVA followed by Holm-Sidak test, $p>0.05$ ). After LPS challenge (post LPS), seizure frequency and total duration of ictal activity were significantly higher in controls with respect to bindarit-treated animals ( $p<$ 0.01). D, Mean seizure duration in bindarit (Bin) and control animals (MC) before (baseline) and after LPS administration. Mean seizure duration was unaffected by LPS + bindarit or LPS + MC treatment (one-way ANOVA, $p=0.7$ ).E, Total time spent in interictal activity per 10 min of recordings (normalized to the baseline period). Before LPS treatment (3-4d), total time spent in interictal activity was unaltered by either bindarit or vehicle with respect to baseline (two-way repeated-measures ANOVA, $p>0.05$ ). After LPS ( $2-4 \mathrm{~h}$ after treatment), the total duration of interictal activity was significantly higher in controls with respect to bindarit-treated animals (two-way repeated-measures ANOVA, $p<0.001$ ). $\boldsymbol{F}$, Number of isolated spikes per 10 min of recording (normalized to the baseline period). Bindarit- and vehicle-treated epileptic mice showed the same range of isolated spike frequency $2-4 \mathrm{~h}$ after LPS administration (two-way repeated-measures ANOVA followed by Holm-Sidak test, $p=0.3) .{ }^{* *} p<0.01 ;{ }^{* * *} p<0.001$.

mRNA levels ( $t$ test, $p<0.01$ ) and robustly increased CCR2 mRNA ( $t$ test, $p=0.0017$ ), suggesting a compensatory response to pharmacological suppression of CCL2 availability (Fig. $8 B$ ). No statistically significant differences were found for $I L-1 \beta$ and TLR2 mRNA expression levels in blood following bindarit treatment (Fig. 8B). qRT-PCR revealed a more widespread reduction of proinflammatory pathways in the hippocampus of bindarittreated mice: CCL2, CCL5, IL1 $\beta$, and TLR2 mRNAs were robustly downregulated, whereas CCR2 mRNA expression was increased ( $t$ test, $p<0.01$ for all comparisons; Fig. $8 C$ ).

CCL2 acts mainly through the G-protein-coupled receptor CCR2 to exert its biological effects (Semple et al., 2010). Therefore, we tested the effects of a potent and selective CCR2 antagonist, RS102895 (Hung et al., 2013; Ren et al., 2015) on LPS-induced seizures (Fig. 9A). We found that systemic RS102895 treatment, but not vehicle, abolished the increase of epileptiform discharges triggered by LPS ( $t$ test, $p<0.01$; Fig. $9 B)$. The enhancement of interictal activity was also counteracted by RS102895 ( $t$ test, $p=0.01$; Fig. $9 C$ ). To examine molecular correlates of LPS-induced CCR2 signaling, we tested whether phosphorylation of the transcription factor NF- $\kappa \mathrm{B}$ (Yang et al., 2003; Mora et al., 2012) is impacted by RS102895. We used immunoblotting to quantify levels of total (p65) and phosphorylated NF- $\kappa$ B (S536 phospho p65) in sclerotic hippocampi from LPS + vehicle and LPS + RS102895 mice (Fig. 9D). We found that, although total levels of p65 were comparable in the two groups ( $t$ test, $p=0.76$ ), RS102895 treatment significantly reduced the fraction of phosphorylated p65 ( $t$ test, $p=0.01$; Fig. $9 E$ ).

To selectively interfere with CCL2 signaling within the epileptic focus, we injected a CCL2 neutralizing antibody (or control IgG) directly into the hippocampus of chronic epileptic animals $30 \mathrm{~min}$ before the LPS challenge (Fig. 10A). As expected, LPS increased SRS frequency and total time spent in ictal activity in control-injected hippocampi (Fig. 10 B,C). Blocking CCL2 locally within the hippocampus completely abolished the LPS-induced increase in seizures (two-way ANOVA followed by Holm-Sidak test, control IgG vs antiCCL2, $p<0.01$; Fig. $10 B, C$ ), whereas mean seizure duration was unaffected (Fig. 10D). LPS-mediated increase of total time spent in interictal activity was also prevented by anti-CCL2 
A
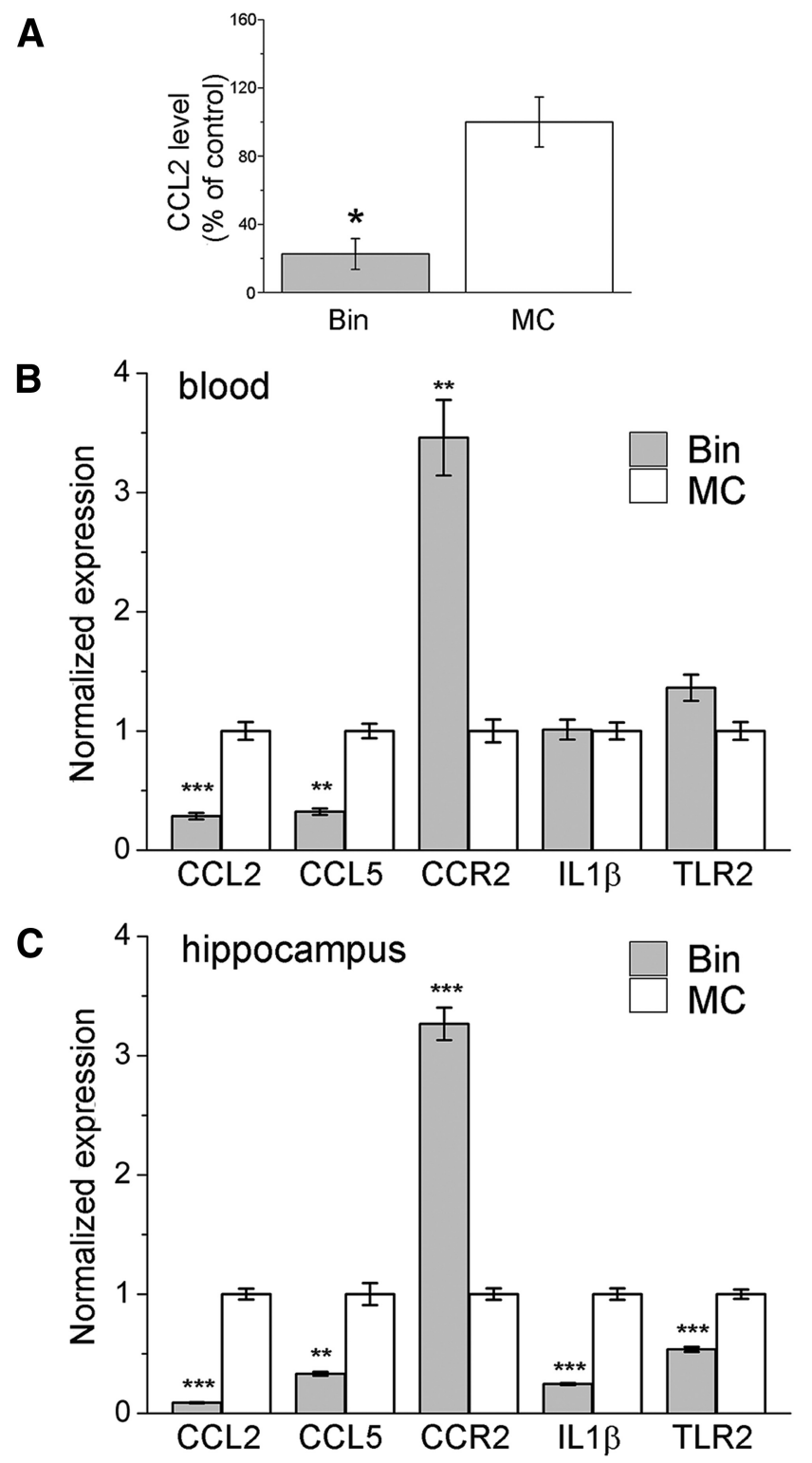

Figure 8. Effect of bindarit on $C \mathrm{CL} 2, \mathrm{CCL} 5, \mathrm{CCR} 2, \mathrm{LL}-1 \beta$, and TLR2 expression. $A$, CCL2 protein levels were reduced by $-77.4 \%$ in serum of bindarit-treated animals compared with control mice ( $t$ test, $p=0.01)$, $4 \mathrm{~h}$ after LPS challenge. $B$, C, CCL2, CCL5, CCR2, IL-1 $\beta$, and TLR2 mRNA levels measured by qRT-PCR in blood (B) and in the hippocampus ( $C$ ) of control (MC) or bindarit (Bin) treated epileptic mice, $4 \mathrm{~h}$ after LPS injection. In the blood, bindarit dampened CCL2 and CCL5 mRNA levels ( $t$ test, $p<0.01$ ) and increased CCR2 expression ( $t$ test, $p<0.01 ; \boldsymbol{B})$. In the hippocampus, bindarit downregulated CCL2, CCL5, IL- $1 \beta$, and TLR2 mRNAs while increasing CCR2 mRNA ( $t$ test, $p<0.0001$ for CCL2, $p<0.02$ for $C C L 5, p<0.0001$ for $I L-1 \beta, p<0.0005$ for TLR2, and $p<0.0001$ for CCR2; C). ${ }^{*} p<0.05 ;{ }^{* *} p<0.01{ }^{* * *} p<0.001$.

injection ( $p<0.05$; Fig. 10E), whereas the number of isolated interictal spikes did not differ between anti-CCL2-treated and control epileptic mice (Fig. 10F).

\section{Discussion}

In this article, we exploited systemic inflammation to perform a molecular screening for the identification of novel inflammatory mediators involved in seizure precipitation. We first examined the functional effect of a LPS challenge in chronically epileptic animals. As a model of chronic seizures, we chose a well-established mouse model based on a single intrahippocampal injection of KA, which induces nonconvulsive status epilepticus (SE) followed by the occurrence of SRS and extensive hippocampal damage (Riban et al., 2002; Gouder et al., 2004; Antonucci et al., 2008, 2009; Maroso et al., 2010; Pallud et al., 2011). Importantly, intracerebral KA administration induces blood-brain barrier disruption and triggers local inflammatory responses (Zattoni et al., 2011). We found that a systemic inflammatory challenge exacerbates the epileptic phenotype, enhancing SRS frequency in KA-injected, chronically epileptic mice. This is in agreement with previous studies showing a proconvulsant effect of a systemic inflammatory stimulus (Sayyah et al., 2003; Galic et al., 2008; Riazi et al., 2008; Friedman and Dingledine, 2011; Zattoni et al., 2011; de Vries et al., 2012; Györffy et al., 2014; Marchi et al., 2014), such as LPS (Sayyah et al., 2003; Galic et al., 2008; Györffy et al., 2014). In particular, LPS administration produces convulsions in rats treated with a normally subconvulsant dose of KA (Heida et al., 2005). Systemic LPS also enhances baseline hippocampal excitability and increases progression of rapid kindling, an effect that is counteracted by neutralization of IL- $1 \beta$ (Auvin et al., 2010). In addition, a growing body of evidence indicates that pilocarpine, one of the most widely used proconvulsant agents, does not require brain access to induce SE, apparently acting as a peripheral proinflammatory agent that triggers seizures (Marchi et al., 2014). Our data expand this notion, demonstrating, for the first time, that a systemic inflammatory challenge is able to worsen SRS occurrence in the intracerebral KA model of MTLE. The present data also add a novel mechanistic insight because LPS increased frequency of ictal events with no effect on seizure duration. Thus, peripheral inflammation appears to target specifically the mechanisms responsible for seizure onset, leaving seizure termination unaffected.

Microarray and protein analysis provided us with an overview of molecular factors regulated by LPS challenge in chronic epileptic animals. Among these factors, CCL2 emerged as a potential mediator of the functional effects of LPS. CCL-2 mRNA was upregulated at the time of LPS-induced seizure aggravation $(4 \mathrm{~h})$ and significantly decreased at the time at which seizure frequency returned to the baseline ( $24 \mathrm{~h}$ ). We found that IL- $1 \beta$ mRNA also showed a similar behavior, in line with the well-known proconvulsant actions of this cytokine (Vezzani et al., 2013). CCL2 protein levels were rapidly upregulated by LPS both in the blood and in the sclerotic hippocampus. Interestingly, we found a significantly more robust rise of CCL2 levels in the epileptic versus naive hippocampus, likely due to a "priming" effect as a consequence of the KA-induced neurodegeneration (Perry and Holmes, 2014). Given the alterations in the blood-brain barrier typical of the KA-lesioned hippocampus (Zattoni et al., 2011), we cannot exclude the possibility that LPS-induced CCL2 upregulation is a consequence of blood-brain barrier disruption and associated cellular recruitment. However, several other inflammatory mediators, such as TNF $\alpha$, interferon- $\gamma$, and IL-10, were upregulated by LPS only in blood but not in hippocampus (Fig. 5), indicating selectivity of the "mirror" response within the epileptic focus. Other studies using much higher doses of LPS (i.e., $2 \mathrm{mg} / \mathrm{kg}$ ) found a more generalized increase in the expression of various proinflammatory genes in the hippocampus (Cazareth et al., 2014). Together, our data show that LPS triggers an exaggerated CCL2 upregulation in the epileptic brain, tightly coupled to seizure precipitation.

To test the functional role of CCL2 in inflammation-induced seizures, we used systemic delivery of bindarit, an indazolic derivative that acts as a powerful modulator of the inflammatory response. 
In particular, it is known that bindarit inhibits transcription of monocyte chemoattractant subfamily of CC chemokines (Cioli et al., 1992; Mirolo et al., 2008), and this is consistent with the decreased levels of both CCL2 and CCL5 mRNA in the blood and hippocampus of bindarit-treated animals (Fig. $8 B, C$ ). Interestingly, our data suggest a compensatory upregulation of the CCL2 receptor (CCR2) at both the peripheral and central levels (Fig. $8 B, C$ ), indicating cellular supersensitivity to CCL2 following its depletion. It is also interesting to note that the hippocampus of bindarit-treated mice displayed a reduced expression of additional inflammatory factors (i.e., IL- $1 \beta$ and TLR2), whose levels were unaffected in the blood. These data suggest that chronic downregulation of CCL 2 by bindarit makes brain structures less responsive to the LPS challenge. This is consistent with the notion that CCL2 can prime microglial cells (Bhattacharyya et al., 2002; Rankine et al., 2006; Perry and Holmes, 2014). Indeed, CCL2 modulates the responsiveness of microglia to acute inflammation, and CCL2 $2^{-/-}$mice display a dampened synthesis of proinflammatory cytokines (e.g., IL-1 $\beta$, TNF $\alpha$ ) following intraparenchymal LPS (Rankine et al., 2006).

To further corroborate the results obtained with systemic depletion of CCL2, we used parenteral administrations of a potent and selective CCR2 antagonist, RS102895, which has been previously used to interfere with CCR2 signaling in the brain (Hung et al., 2013; Ren et al., 2015). We found that administration of RS102895 blocked the enhancement of epileptiform activity and the phosphorylation of NF- $\kappa$ B (p65 subunit) induced by LPS. These data suggest the potential of CCR2 antagonists for the treat-

ment of inflammation-induced seizures. We also targeted CCL2 directly into the epileptic focus, using blocking antibodies delivered at the time of LPS delivery. Results were clear in indicating a marked suppression of the LPS-induced seizure enhancement with the functionally blocking, but not control, antibodies. In conclusion, both systemic and local interference with CCL2/CCR2 signaling yields potent anticonvulsant effects following systemic inflammation. These data show a previously unrecognized role for CCL2 in mediating seizure upregulation following systemic inflammation.

Several mechanisms may account for the seizure-promoting action of CCL2. First, CCL2 may exert direct effects on neuronal excitability. Indeed, CCL2 alters electrophysiological properties and $\mathrm{Ca}^{2+}$ signaling in cerebellar neurons (van Gassen et al., 2005), reduces inhibitory responses in spinal cord neurons (Gosselin et al., 2005), and potentiates excitatory post synaptic currents in the Schaffer collateral pathway of the hippocampus in vitro (Zhou et al., 2011). These latter effects are mediated by activation of the p38 MAP kinase pathway (Cho and Gruol, 2008). Second, CCL2 may also increase seizure frequency indirectly, acting as a priming stimulus for the synthesis of other proinflammatory factors in the brain. As described above, depletion of CCL2 may result in

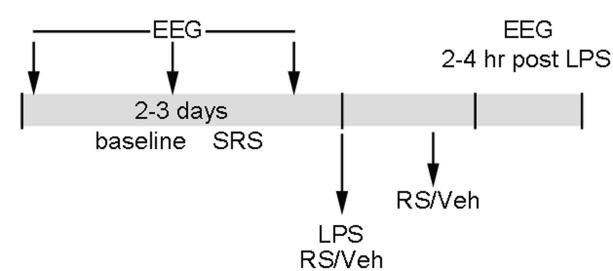

C

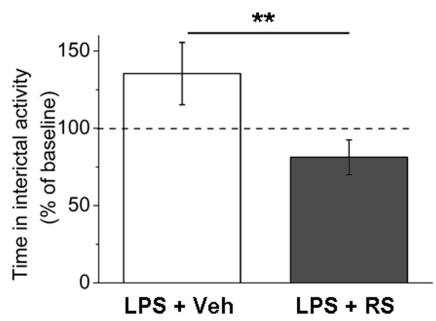

\section{E}

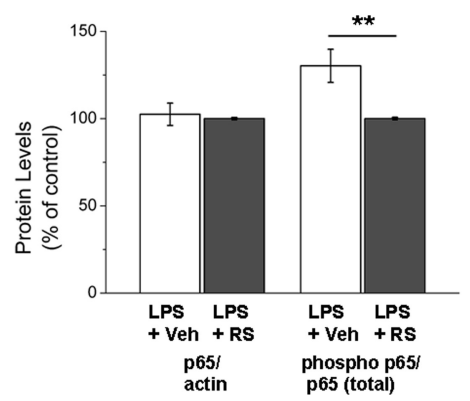

Figure 9. Systemic delivery of a CCR2 receptor antagonist prevents the LPS-induced enhancement of epileptic activity. $\boldsymbol{A}$, Experimental protocol. $\boldsymbol{B}$, Frequency of epileptiform discharges (normalized to the baseline period) in animals treated with vehicle veh) or RS102895 (RS), 2 - 4 h after LPS challenge. RS102895 prevents the enhancement of epileptic activity ( $t$ test, $p<0.01$ ). $C_{,}$

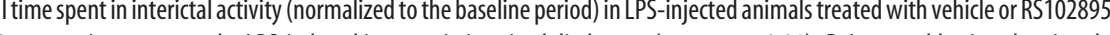
levels of total p65, phosphorylated (phospho) p65, and $\beta$-actin (loading control) in the sclerotic hippocampus of a representative $p=0.01$ ) indicates consistent reduction of the fraction of phosphorylated p65 in LPS + RS102895 (RS) mice compared with LPS + vehicle (veh). ${ }^{* *} p \leq 0.01$.

lowered synthesis and signaling of IL- $1 \beta$, whose involvement in seizure precipitation is well documented (Balosso et al., 2008; Maroso et al., 2011; Vezzani et al., 2011). Here, we have demonstrated that CCR2 is expressed in activated microglia/macrophages within the sclerotic hippocampus (Fig. 6). As activated microglial cells are prominently involved in the production and release of IL- $1 \beta$ in epileptic tissue (Vezzani et al., 1999), these data suggest that CCL2 may increase seizures via IL- $1 \beta$. Thus, the CCL2 pathway may act as a master regulator of inflammatory processes in the epileptic brain by both directly promoting hyperexcitability and regulating the activity of downstream inflammatory effectors. Finally, CCL2 might also be involved in neuropathological changes that accompany seizures, as indicated by a recent study (Hung et al., 2013). After pilocarpine-induced SE, CCL2 mRNA and protein were significantly upregulated in the dentate gyrus, whereas the CCL2 receptor CCR2 was expressed in ectopic progenitors of hilar neurons. Systemic blockade of CCR2 with RS102895 attenuated the ectopic migration of neuronal progenitors into the hilus, indicating a crucial role of CCL2/CCR2 interaction in neuronal migration following seizures (Hung et al., 2013).

CCL2 elevations have been previously demonstrated in the brain of patients with intractable epilepsy (Choi et al., 2009) and following 
A

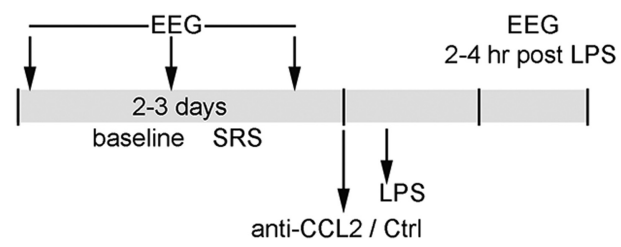

B
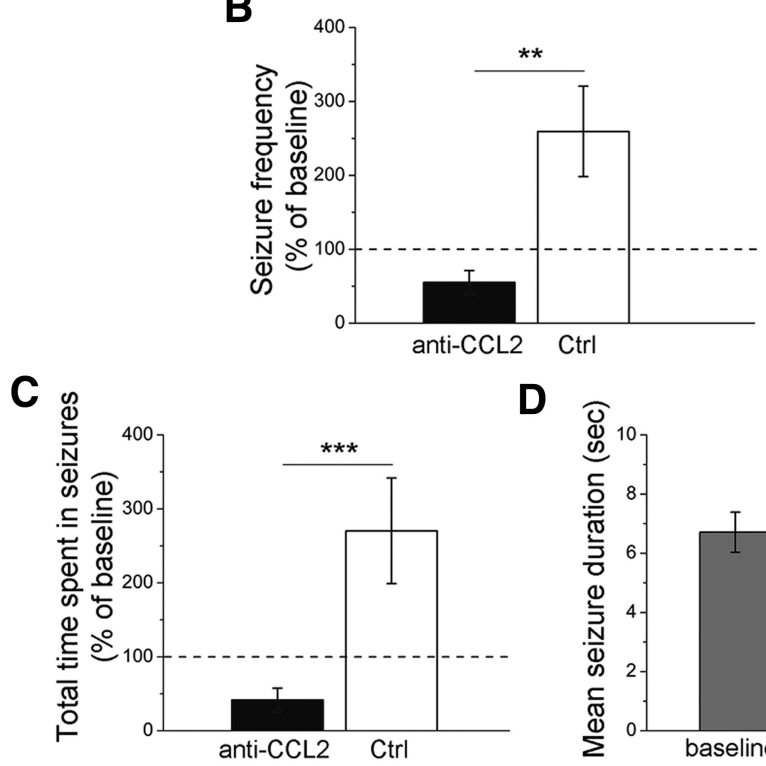

E

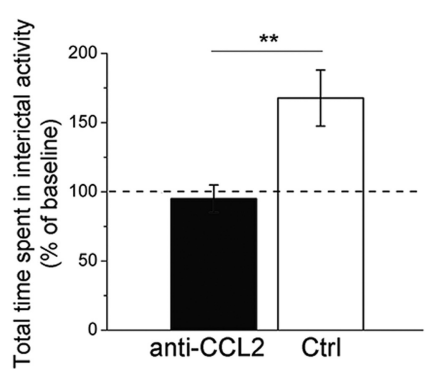

D

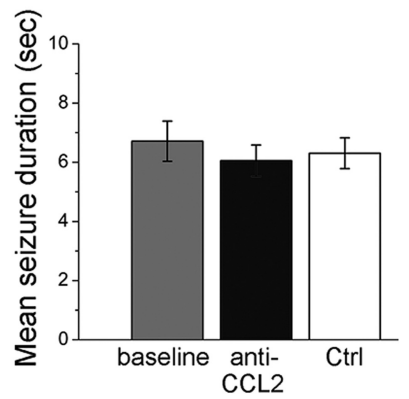

$\mathbf{F}$

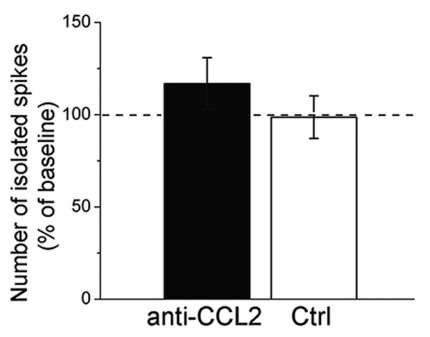

Figure 10. Intrahippocampal injection of a CCL2 neutralizing antibody completely abrogates the increase in seizures following LPS. A, Experimental protocol. $\boldsymbol{B}$, Seizure frequency in anti-CCL2 or control lgG-injected animals (Ctrl), $2-4 \mathrm{~h}$ after LPS administration. In control animals, seizure frequency is significantly higher than in anti-CCL2 injected animals (two-way ANOVA followed by Holm-Sidak test, $p<0.01$ ). C, Total time spent in seizures in anti-CCL2 or control lgG-injected (Ctrl) animals, $2-4 \mathrm{~h}$ after LPS administration. In control lgG-injected animals (Ctrl), total duration of ictal activity is significantly higher than in anti-CCL2 injected animals (two-way ANOVA followed by Holm-Sidak test, $p<0.001$ ). $\boldsymbol{D}$, Mean seizure duration in anti-CCL2-injected and control animals before (baseline) and after LPS administration. Mean seizure duration was unaffected by anti-CCL2 + LPS treatment (one way ANOVA, $p=0.3$ ). $\boldsymbol{E}$, Total time spent in interictal activity (normalized to the baseline period). Anti-CCL2 prevented the LPS-mediated increase of interictal activity (two-way repeated-measures ANOVA followed by Holm-Sidak test, $p<0.01$ ). $\boldsymbol{F}$, Number of isolated spikes per $10 \mathrm{~min}$ of recording (normalized to the baseline period). No difference was found between anti-CCL2 injected and control IgG-injected (Ctrl) epileptic mice, 2-4 h after LPS administration (two-way repeatedmeasures ANOVA, $p=0.7)$. ${ }^{* *} p<0.01 ;{ }^{* *} p<0.001$.

experimental seizures in animals (Foresti et al., 2009). Here, we provide the first demonstration of a key functional role for CCL2 in seizure precipitation. Drugs interfering with CCL2 signaling are currently under development for several inflammatory brain disorders (Semple et al., 2010) and may be tested in epileptic syndromes that remain resistant to currently available medications.

\section{References}

Antonucci F, Di Garbo A, Novelli E, Manno I, Sartucci F, Bozzi Y, Caleo M (2008) Botulinum neurotoxin E (BoNT/E) reduces CAl neuron loss and granule cell dispersion, with no effects on chronic seizures, in a mouse model of temporal lobe epilepsy. Exp Neurol 210:388-401. CrossRef Medline

Antonucci F, Bozzi Y, Caleo M (2009) Intrahippocampal infusion of botu- linum neurotoxin E (BoNT/E) reduces spontaneous recurrent seizures in a mouse model of mesial temporal lobe epilepsy. Epilepsia 50: 963-966. CrossRef Medline

Aronica E, Gorter JA (2007) Gene expression profile in temporal lobe epilepsy. Neuroscientist 13:100-108. CrossRef Medline

Auvin S, Shin D, Mazarati A, Sankar R (2010) Inflammation induced by LPS enhances epileptogenesis in immature rat and may be partially reversed by IL1RA. Epilepsia 51 [Suppl 3]:34-38.

Balosso S, Maroso M, Sanchez-Alavez M, Ravizza T, Frasca A, Bartfai T, Vezzani A (2008) A novel non-transcriptional pathway mediates the proconvulsive effects of interleukin-1beta. Brain 131:3256-3265. CrossRef Medline

Bhattacharyya S, Ghosh S, Dasgupta B, Mazumder D, Roy S, Majumdar S (2002) Chemokine-induced leishmanicidal activity in murine macrophages via the generation of nitric oxide. J Infect Dis 185:1704-1708. CrossRef Medline

Cazareth J, Guyon A, Heurteaux C, Chabry J, Petit-Paitel A (2014) Molecular and cellular neuroinflammatory status of mouse brain after systemic lipopolysaccharide challenge: importance of CCR2/CCL2 signaling. J Neuroinflammation 11:132. CrossRef Medline

Cho J, Gruol DL (2008) The chemokine CCL2 activates p38 mitogen-activated protein kinase pathway in cultured rat hippocampal cells. J Neuroimmunol 199:94-103. CrossRef Medline

Choi J, Nordli DR Jr, Alden TD, DiPatri A Jr, Laux L, Kelley K, Rosenow J, Schuele SU, Rajaram V, Koh S (2009) Cellular injury and neuroinflammation in children with chronic intractable epilepsy. J Neuroinflammation 6:38. CrossRef Medline

Cioli V, Ciarniello MG, Guglielmotti A, Luparini MR, Durando L, Martinelli B, Catanese B, Fava L, Silvestrini B (1992) A new protein antidenaturant agent, bindarit, reduces secondary phase of adjuvant arthritis in rats. J Rheumatol 19:1735-1742. Medline

Cross JH (2012) Fever and fever-related epilepsies. Epilepsia 53 [Suppl 4]:3-8.

Cunningham C (2013) Microglia and neurodegeneration: the role of systemic inflammation. Glia 61:71-90. CrossRef Medline

Devinsky O, Vezzani A, Najjar S, De Lanerolle NC, Rogawski MA (2013) Glia and epilepsy: excitability and inflammation. Trends Neurosci 36:174-184. CrossRef Medline

de Vries HE, Kooij G, Frenkel D, Georgopoulos S, Monsonego A, Janigro D (2012) Inflammatory events at blood-brain barrier in neuroinflammatory and neurodegenerative disorders: implications for clinical disease. Epilepsia 53 [Suppl 6]:45-52.

Fabene PF, Navarro Mora G, Martinello M, Rossi B, Merigo F, Ottoboni L, Bach S, Angiari S, Benati D, Chakir A, Zanetti L, Schio F, Osculati A, Marzola P, Nicolato E, Homeister JW, Xia L, Lowe JB, McEver RP, Osculati F, et al. (2008) A role for leukocyte-endothelial adhesion mechanisms in epilepsy. Nat Med 14:1377-1383. CrossRef Medline

Foresti ML, Arisi GM, Katki K, Montañez A, Sanchez RM, Shapiro LA (2009) Chemokine CCL2 and its receptor CCR2 are increased in the hippocampus following pilocarpine-induced status epilepticus. J Neuroinflammation 6:40. CrossRef Medline

Friedman A, Dingledine R (2011) Molecular cascades that mediate the influence of inflammation on epilepsy. Epilepsia 52 [Suppl 3]:33-39.

Fujimoto H, Sangai T, Ishii G, Ikehara A, Nagashima T, Miyazaki M, Ochiai A 
(2009) Stromal MCP-1 in mammary tumors induces tumor-associated macrophage infiltration and contributes to tumor progression. Int J Cancer 125:1276-1284. CrossRef Medline

Galic MA, Riazi K, Heida JG, Mouihate A, Fournier NM, Spencer SJ, Kalynchuk LE, Teskey GC, Pittman QJ (2008) Postnatal inflammation increases seizure susceptibility in adult rats. J Neurosci 28:6904-6913. CrossRef Medline

Ge S, Shrestha B, Paul D, Keating C, Cone R, Guglielmotti A, Pachter JS (2012) The CCL2 synthesis inhibitor bindarit targets cells of the neurovascular unit, and suppresses experimental autoimmune encephalomyelitis. J Neuroinflammation 9:171. CrossRef Medline

Gosselin RD, Varela C, Banisadr G, Mechighel P, Rostene W, Kitabgi P, Melik-Parsadaniantz S (2005) Constitutive expression of CCR2 chemokine receptor and inhibition by MCP-1/CCL2 of GABA-induced currents in spinal cord neurones. J Neurochem 95:1023-1034. CrossRef Medline

Gouder N, Scheurer L, Fritschy JM, Boison D (2004) Overexpression of adenosine kinase in epileptic hippocampus contributes to epileptogenesis. J Neurosci 24:692-701. CrossRef Medline

Györffy B, Kovács Z, Gulyássy P, Simor A, Völgyi K, Orbán G, Baracskay P, Szabó Z, Janáky T, Dobolyi A, Juhász G, Czurkó A, Kékesi KA (2014) Brain protein expression changes in WAG/Rij rats, a genetic rat model of absence epilepsy after peripheral lipopolysaccharide treatment. Brain Behav Immun 35:86-95. CrossRef Medline

Heida JG, Teskey GC, Pittman QJ (2005) Febrile convulsions induced by the combination of lipopolysaccharide and low-dose kainic acid enhance seizure susceptibility, not epileptogenesis, in rats. Epilepsia 46:1898-1905. CrossRef Medline

Hung YW, Lai MT, Tseng YJ, Chou CC, Lin YY (2013) Monocyte chemoattractant protein- 1 affects migration of hippocampal neural progenitors following status epilepticus in rats. J Neuroinflammation 10:11. CrossRef Medline

Mainardi M, Pietrasanta M, Vannini E, Rossetto O, Caleo M (2012) Tetanus neurotoxin-induced epilepsy in mouse visual cortex. Epilepsia 53:e132e136. CrossRef Medline

Marchi N, Granata T, Janigro D (2014) Inflammatory pathways of seizure disorders. Trends Neurosci 37:55-65. CrossRef Medline

Maroso M, Balosso S, Ravizza T, Liu J, Aronica E, Iyer AM, Rossetti C, Molteni M, Casalgrandi M, Manfredi AA, Bianchi ME, Vezzani A (2010) Toll-like receptor 4 and high-mobility group box-1 are involved in ictogenesis and can be targeted to reduce seizures. Nat Med 16:413-419. CrossRef Medline

Maroso M, Balosso S, Ravizza T, Iori V, Wright CI, French J, Vezzani A (2011) Interleukin-1beta biosynthesis inhibition reduces acute seizures and drug resistant chronic epileptic activity in mice. Neurotherapeutics 8:304-315. CrossRef Medline

Mirolo M, Fabbri M, Sironi M, Vecchi A, Guglielmotti A, Mangano G, Biondi G, Locati M, Mantovani A (2008) Impact of the anti-inflammatory agent bindarit on the chemokinome: selective inhibition of the monocyte chemotactic proteins. Eur Cytokine Netw 19:119-122. CrossRef Medline

Mora E, Guglielmotti A, Biondi G, Sassone-Corsi P (2012) Bindarit: an antiinflammatory small molecule that modulates the NFkappaB pathway. Cell Cycle 11:159-169. CrossRef Medline

Pallud J, Häussler U, Langlois M, Hamelin S, Devaux B, Deransart C, Depaulis A (2011) Dentate gyrus and hilus transection blocks seizure propagation and granule cell dispersion in a mouse model for mesial temporal lobe epilepsy. Hippocampus 21:334-343. CrossRef Medline

Pernot F, Heinrich C, Barbier L, Peinnequin A, Carpentier P, Dhote F, Baille V, Beaup C, Depaulis A, Dorandeu F (2011) Inflammatory changes during epileptogenesis and spontaneous seizures in a mouse model of mesiotemporal lobe epilepsy. Epilepsia 52:2315-2325. CrossRef Medline

Perry VH, Holmes C (2014) Microglial priming in neurodegenerative disease. Nat Rev Neurol 10:217-224. CrossRef Medline

Rankine EL, Hughes PM, Botham MS, Perry VH, Felton LM (2006) Brain cytokine synthesis induced by an intraparenchymal injection of LPS is reduced in MCP-1-deficient mice prior to leucocyte recruitment. Eur J Neurosci 24:77-86. CrossRef Medline

Ren F, Jiao H, Cai H (2015) Analgesic effect of intrathecal administration of chemokine receptor CCR2 antagonist is related to change in spinal NR2B, nNOS, and SIGIRR expression in rat with bone cancer pain. Cell Biochem
Biophys. Advance online publication. Retrieved Feb. 5, 2015. doi: 10.1007/s12013-014-0510-7. CrossRef Medline

Riazi K, Galic MA, Kuzmiski JB, Ho W, Sharkey KA, Pittman QJ (2008) Microglial activation and TNFalpha production mediate altered CNS excitability following peripheral inflammation. Proc Natl Acad Sci U S A 105:17151-17156. CrossRef Medline

Riban V, Bouilleret V, Pham-Lê BT, Fritschy JM, Marescaux C, Depaulis A (2002) Evolution of hippocampal epileptic activity during the development of hippocampal sclerosis in a mouse model of temporal lobe epilepsy. Neuroscience 112:101-111. CrossRef Medline

Sayyah M, Javad-Pour M, Ghazi-Khansari M (2003) The bacterial endotoxin lipopolysaccharide enhances seizure susceptibility in mice: involvement of proinflammatory factors: nitric oxide and prostaglandins. Neuroscience 122:1073-1080. CrossRef Medline

Semple BD, Kossmann T, Morganti-Kossmann MC (2010) Role of chemokines in CNS health and pathology: a focus on the CCL2/CCR2 and CXCL8/CXCR2 networks. J Cereb Blood Flow Metab 30:459-473. CrossRef Medline

Sgadò P, Provenzano G, Dassi E, Adami V, Zunino G, Genovesi S, Casarosa S, Bozzi Y (2013) Transcriptome profiling in engrailed-2 mutant mice reveals common molecular pathways associated with autism spectrum disorders. Mol Autism 4:51. CrossRef Medline

Shi C, Pamer EG (2011) Monocyte recruitment during infection and inflammation. Nat Rev Immunol 11:762-774. CrossRef Medline

Stamatovic SM, Keep RF, Mostarica-Stojkovic M, Andjelkovic AV (2006) CCL2 regulates angiogenesis via activation of Ets-1 transcription factor. J Immunol 177:2651-2661. CrossRef Medline

Teeling JL, Felton LM, Deacon RM, Cunningham C, Rawlins JN, Perry VH (2007) Sub-pyrogenic systemic inflammation impacts on brain and behavior, independent of cytokines. Brain Behav Immun 21:836-850. CrossRef Medline

Tripathi PP, Sgadò P, Scali M, Viaggi C, Casarosa S, Simon HH, Vaglini F, Corsini GU, Bozzi Y (2009) Increased susceptibility to kainic acidinduced seizures in Engrailed-2 knockout mice. Neuroscience 159:842849. CrossRef Medline

van Gassen KL, Netzeband JG, de Graan PN, Gruol DL (2005) The chemokine CCL2 modulates $\mathrm{Ca}^{2+}$ dynamics and electrophysiological properties of cultured cerebellar Purkinje neurons. Eur J Neurosci 21:2949-2957. CrossRef Medline

Vannini E, Restani L, Pietrasanta M, Panarese A, Mazzoni A, Rossetto O, Middei S, Micera S, Caleo M (2015) Altered sensory processing and dendritic remodeling in hyperexcitable visual cortical networks. Brain Struct Funct. Advance online publication. Retrieved Jul. 12, 2015. doi: 10.1007/ s00429-015-1080-1. CrossRef Medline

Vezzani A, Conti M, De Luigi A, Ravizza T, Moneta D, Marchesi F, De Simoni MG (1999) Interleukin-1beta immunoreactivity and microglia are enhanced in the rat hippocampus by focal kainate application: functional evidence for enhancement of electrographic seizures. J Neurosci 19:50545065. Medline

Vezzani A, Moneta D, Conti M, Richichi C, Ravizza T, De Luigi A, De Simoni MG, Sperk G, Andell-Jonsson S, Lundkvist J, Iverfeldt K, Bartfai T (2000) Powerful anticonvulsant action of IL-1 receptor antagonist on intracerebral injection and astrocytic overexpression in mice. Proc Natl Acad Sci U S A 97:11534-11539. CrossRef Medline

Vezzani A, Maroso M, Balosso S, Sanchez MA, Bartfai T (2011) IL-1 receptor/Toll-like receptor signaling in infection, inflammation, stress and neurodegeneration couples hyperexcitability and seizures. Brain Behav Immun 25:1281-1289. CrossRef Medline

Vezzani A, Aronica E, Mazarati A, Pittman QJ (2013) Epilepsy and brain inflammation. Exp Neurol 244:11-21. CrossRef Medline

Yang F, Tang E, Guan K, Wang CY (2003) IKK beta plays an essential role in the phosphorylation of RelA/p65 on serine 536 induced by lipopolysaccharide. J Immunol 170:5630-5635. CrossRef Medline

Zattoni M, Mura ML, Deprez F, Schwendener RA, Engelhardt B, Frei K, Fritschy JM (2011) Brain infiltration of leukocytes contributes to the pathophysiology of temporal lobe epilepsy. J Neurosci 31:4037-4050. CrossRef Medline

Zhou Y, Tang H, Liu J, Dong J, Xiong H (2011) Chemokine CCL2 modulation of neuronal excitability and synaptic transmission in rat hippocampal slices. J Neurochem 116:406-414. CrossRef Medline 